IFN Working Paper No. 1003, 2014

\title{
Political Selection in China: the Complementary Roles of Connections and Performance
}

Ruixue Jia, Masayuki Kudamatsu and David Seim 


\title{
Political Selection in China: the Complementary Roles of Connections and Performance *
}

\author{
Ruixue Jia†, Masayuki Kudamatsu; and David Seim ${ }^{\S}$
}

January 16, 2014

\begin{abstract}
Who becomes a top politician in China? We focus on provincial leaders - a pool of candidates for top political office - and examine how their chances of promotion depend on their performance in office and connections with top politicians. Our empirical analysis, based on the curriculum vitae of Chinese politicians, shows that connections and performance are complements in the Chinese political selection process. This complementarity is stronger the younger provincial leaders are relative to their connected top leaders. To provide one plausible interpretation of these empirical findings, we propose a simple theory in which the complementarity arises because connections foster loyalty of junior officials to senior ones, thereby allowing incumbent top politicians to select competent provincial leaders without risking being ousted. Auxiliary evidence suggests that the documented promotion pattern does not distort the allocation of talent. Our findings shed some light on why a political system known for patronage can still select competent leaders.
\end{abstract}

\footnotetext{
${ }^{*}$ We thank Philippe Aghion, Tim Besley, Loren Brandt, Antonio Ciccone, Tom Cunningham, Claudio Ferraz, Lucie Gadenne, Nicola Gennaioli, Maitreesh Ghatak, Henrik Kleven, Anna Larsson Seim, Shi Li, Rocco Macchiavello, Rob McMillan, Stelios Michalopoulos, Dirk Niepelt, Elena Nikolova, Peter Nilsson, Gerard Padro-i-Miquel, Mårten Palme, Albert Park, Torsten Persson, Per Pettersson-Lidbom, Gerard Roland, David Strömberg, Dan Tortorice, Shing-Yi Wang, Peter Zeitz, Li-An Zhou, Fabrizio Zilibotti, and seminar participants at the CEPR/BREAD/AMID Conference on Development Economics in 2011, Barcelona Development Economics Workshop in 2012, China Meeting of the Econometric Society 2013, Tartu, Gothenburg, Zurich, EBRD, Pennsylvania, Edinburgh, Strathclyde, Singapore Management University, National Graduate Institute of Policy Studies, Osaka, and Hong Kong University of Science and Technology, IIES Stockholm, and Shandong University for helpful comments and suggestions. We also thank Jin Wang for sharing the data and Christina Lönnblad for editorial assistance. Financial support from ERC grant 249580 (Kudamatsu) and Jan Wallander and Tom Hedelius Foundation (Jia and Seim) is gratefully acknowledged.

${ }^{\dagger} \mathrm{IR} / \mathrm{PS}$, University of California San Diego

${ }^{\ddagger}$ IIES, Stockholm University

${ }^{\S}$ Department of Economics, University of Toronto, and Research Institute of Industrial Economics.
} 


\section{Introduction}

Who becomes a top politician in China? The spectacular economic performance of the Chinese economy in the past few decades suggests that the politicians selected to rule the country may have been conducive to growth, or at least not detrimental to economic development. What has made it possible for China to place such politicians in top government positions? The existing literature on political selection remains inconclusive as to what determines the selection of politicians in a non-democratic country like China. ${ }^{1}$ In this paper, we contribute to this literature by examining factors determining the promotion of China's provincial leaders, a pool of candidates for top positions in the central government. ${ }^{2}$ In particular, we focus on two determinants of promotion often discussed by academics and observers of Chinese politics: performance and connections.

On the one hand, several empirical studies suggest that the political selection in China is based on meritocracy: provincial leaders are more likely to be promoted if they achieve higher economic growth in their province (Bo 1996, 2002, Maskin et al. 2000, Li and Zhou 2005, Chen et al. 2005). ${ }^{3}$ On the other hand, anecdotal evidence and a systematic empirical analysis by Shih et al. (2012) imply that patronage is key: it is the social connections to top leaders that determine the chance of promotion. ${ }^{4}$ These two views also feature prominently in the mass-media coverage of Chinese politics. ${ }^{5}$ However, the debate over meritocracy versus

\footnotetext{
${ }^{1}$ Most studies in the literature on political selection focus on democracy. See Caselli and Morelli (2004), Messner and Polborn (2004), Besley (2005), Mattozzi and Merlo (2008, 2011), Ferraz and Finan (2011), Galasso and Nannicini (2011), and Besley et al. (2012) among others. Acemoglu et al. (2010) and Besley and Reynal-Querol (2011) compare democracies and non-democracies in terms of political selection. Egorov and Sonin (2011) focus on the dictator's trade-off between choosing competent and loyal politicians as his subordinates. Garcia-Jimeno and Robinson (2011) provide empirical evidence on the type of politicians appointed to mayorship in 19th century Colombia. Francois et al. (2012) analyze how African dictators allocate cabinet minister positions across different ethnic groups.

${ }^{2}$ Since China is ruled by the Communist Party, the political selection process is equivalent to the promotion of party officials. Many top leaders in China used to be provincial leaders. For example, the three most recent General Secretaries of the Chinese Communist Party (the highest ranked politician in China) all used to be provincial leaders: Shanghai (one of the four municipalities with provincial status) for Jiang Zemin, Guizhou and Tibet for Hu Jintao, and Zhejiang and Fujian for Xi Jinping.

${ }^{3}$ Whiting (2000) and Edin (2003) provide similar evidence for township leaders, and Landry (2008) for mayors. Huang (1998) appears to be the first to argue that the Chinese central government uses performancebased promotion to overcome the difficulty in controlling local government officials. Blanchard and Shleifer (2001) apply this argument to explain economic growth in China. Li (2012) provides evidence that the performance-based promotion scheme for provincial leaders drives business cycles in China. See also Xu (2011) for a thorough survey of this literature.

${ }^{4}$ Jiang Zemin, General Secretary from 1989 to 2002, is well-known for having promoted his former colleagues when he was the leader of Shanghai (those promoted are thus known as the Shanghai clique). Hu Jintao, who succeeded Jiang in 2002, is also widely known for having promoted his former colleagues while being the leader of the Communist Youth League, a youth organization of the Chinese Communist Party (such promoted officials are known as tuanpai).

${ }^{5}$ For example, in the lead-up of the 18th National Congress of the Communist Party held in November 2012, where many promotion decisions would be made, the New York Times published articles emphasizing both aspects. See, for instance, Zhang (2012) for the meritocracy view and Wong (2012) for the patronage view.
} 
patronage in political selection is puzzling. If China's political system is based on patronage, how has the system been successful at selecting leaders who have played a critical role in promoting growth? Conversely, If China's political selection is essentially a meritocracy, why do observers emphasize the roles of connections?

In this paper, we argue that considering either or both of these two aspects in isolation fails to take into account the possibility of important interaction effects between connections and performance in the promotion process. By using data on connections constructed from the curriculum vitae of Chinese politicians, we show empirically that connections and performance are complements in the Chinese political selection process. We also find that this complementarity is stronger the younger provincial leaders are relative to their connected top leaders in the central government.

To provide one plausible explanation for this empirical pattern, we propose a simple theory in which the complementarity arises because connections foster loyalty of junior officials to senior ones, allowing incumbent top politicians to select competent provincial leaders without risking being ousted. As the interdependent roles of connections and performance in the promotion decision have been neglected in the previous literature, we first present a simple model of promotion to illustrate a few theoretical mechanisms through which connections and performance may jointly affect the chance of promotion. In this model, promotion acts as a screening device. ${ }^{6}$ Connections play three possible roles: loyalty-fostering (increasing the survival probability of top politicians), ability-learning (conveying information about the ability of candidates for promotion) and communication-enhancing (conveying information about the provincial economy through close communication between top politicians and provincial leaders). When either the loyalty-fostering role or the communication-enhancing role of connections dominates, connections and performance complement each other in increasing the chance of promotion. If the ability-learning role dominates, on the other hand, the two determinants of promotion are substitutes. While other mechanisms may also explain the interdependence of connections and performance (see Section 3.3), we focus on these channels because we believe they are most relevant, and because data are available for testing their implications.

To investigate empirically whether connections and performance are complements or substitutes in the Chinese political selection process, we construct a sample of provincial leaders who held office between 1993 and 2009. Using the curriculum vitae of Communist Party officials, we measure connections between these provincial leaders and the top seven or nine party officials at the center based on whether they used to work in the same branch of the party or the government in the same period. ${ }^{7}$ To measure performance, we follow the literature and use the real GDP growth of the province that each leader rules.

We find that connected provincial leaders are, on average, significantly more likely to be

\footnotetext{
${ }^{6}$ In Appendix Section A.3, we also present a model of promotion where promotion acts as an incentive scheme for provincial leaders to boost economic growth.

${ }^{7}$ We also measure connections based on education and birth place, but these measures do not have any significant correlations with promotion. See Section 5.4.
} 
promoted than unconnected ones. However, this difference is driven by a stronger positive correlation between promotion and economic growth for connected officials. Quantitatively, the difference between the two groups is large. A one standard deviation increase in growth raises the probability of promotion by 5.3 percentage points more for connected officials than for unconnected ones, where the sample average promotion rate is 7 percent. Weaklyperforming provincial leaders are unlikely to be promoted irrespective of their connections, while connections increase the likelihood of promotion for strongly-performing provincial leaders. In other words, connections and performance are complements in the promotion of provincial leaders in China.

Connections may be endogenous. For example, connected officials may differ from unconnected ones in individual and provincial characteristics. Our results are, however, remarkably robust to controlling for a wide range of covariates (such as the provincial economic growth before assuming office) and their interactions with provincial economic growth, which may confound the effect of connections. Another concern is that connected provincial leaders may be able to obtain the support from the central government to boost their province's growth. However, we do not find evidence that connections are correlated with the central government's support (fiscal transfers, state-owned bank loans, and the Special Economic Zone policy) to boost provincial economic growth. Finally, connections may be an indication of being on the elite career track. We find that connections to other high-ranked politicians who do not decide on promotions do not display a similar pattern of correlation with promotion. This suggests that the documented correlation of connections and promotions is driven by whether the provincial leader's connections hold power in the highest decision-making body in the Communist Party, which is plausibly beyond the control of each provincial leader.

Provincial economic growth is also endogenous. Exploiting its exogenous variation, however, does not help us answer the question of whether performance affects promotion. An exogenous shock to economic growth is, by definition, beyond the control of provincial leaders, and its effect on promotion may reflect whether top leaders in China are mistaking such shocks for strong performance, a question that is of less importance. ${ }^{8}$ We instead investigate whether provincial economic growth correlates with other factors such as the strength of connections. We find no such evidence.

In light of our theoretical framework, the evidence relating to the complementarity of connections and performance is consistent with both the loyalty-fostering and the communicationenhancing roles of connections. We further investigate auxiliary predictions of the two channels. First, as a test of the loyalty-fostering channel, we explore age differences of the connected pairs. Compared to peers of similar ages, who may compete with each other, a senior-junior connection is more likely to be the indicator of loyalty. We find that the complementarity is stronger for the connected pairs where provincial leaders are substantially younger than the PSC members, providing evidence in support of the loyalty-fostering

\footnotetext{
${ }^{8}$ In other contexts such as CEO pay, exploiting exogenous shocks in performance can be an effective empirical strategy. See Bertrand and Mullainathan (2001), for example.
} 
role of connections. Second, as a test of the communication-enhancing channel, we exploit the provincial leader's tenure. The degree of complementarity due to the communicationenhancing role of connections should attenuate during the provincial leader's tenure, because the longer the tenure, the less noisy the provincial growth measure becomes as a signal of the ability. We do not find this to be the case, which provides evidence against the communication-enhancing role of connections.

Finally, we investigate whether the documented promotion pattern distorts the allocation of talent. By looking at a subset of provincial leaders who hold provincial leadership positions more than once (so that we can measure their performance in terms of provincial economic growth after the promotion decision), we find suggestive evidence that the promotion pattern does not distort the allocation of talent within the Communist Party.

Our contribution to the political economy literature is two-fold. To the best of our knowledge, we are the first to document that connections and performance complement each other in the political selection process in China or a non-democratic country in general. We are also the first to suggest that social connections among politicians may be critical for selecting competent leaders in the absence of democratic elections.

Our paper is also related to an emerging literature on the impact of social connections to politicians (Fisman 2001, Khwaja and Mian 2005, and Blanes i Vidal et al. 2011, among others). In the context of China, Shih $(2004,2008)$ investigates the impact of connections (measured in a similar way to ours) on the loan-to-deposit ratio of each province, interpreted as the support from the central government. Persson and Zhuravskaya (2012) find that provincial leaders who rule their native province invest less in infrastructure and spend more on education and health than those not born in the province they rule. Different from these studies, we focus on the interplay of connections and performance as determinants of political selection.

Our study also speaks to the role of connections and performance in the selection process beyond the political arena. Li (2013) studies the determinants of research grant approval and finds that the applicant's connections with reviewers complement the quality of research projects. She interprets this finding as reviewers being more informed about the quality of research of their connected applicants, a mechanism equivalent of the communicationenhancing role of connections in our theoretical framework. In her context, reviewers are unlikely to be threatened by successful grant applicants. More generally, however, the complementarity between connections and performance may emerge due to the loyalty-fostering role of connections. Our theoretical framework encompasses both of these roles of connections that imply complementarity, and we suggest an empirical methodology that can disentangle these channels.

The next section briefly introduces relevant aspects of the Chinese political system. Section 3 then lays out a simple theoretical framework describing how connections and performance may interact with each other to affect the probability of promotion. Section 4 describes the data and the empirical strategy. Section 5 provides evidence that connections and performance are complements. Section 6 then offers further evidence that the 
complementarity is stronger the younger provincial leaders are relative to their connected top politicians in the central government. Section 7 provides suggestive evidence that the promotion pattern does not distort the allocation of talent within the Chinese government. Section 8 concludes the paper.

\section{Institutional Background}

China's highest decision-making body is the Politburo Standing Committee (PSC) of the Communist Party of China. It consists of seven (or nine during 2002-2012) party officials including the General Secretary (the head of the Communist Party) and the Premier (the head of the Chinese government). Although the procedure of its decision-making is not public information, it is commonly believed that members of the PSC meet once a week and make decisions by consensus (Shirk 1993, Miller 2004, McGregor 2010). Among other things, the committee decides on which provincial leaders to promote.

Each of the 31 provinces of China (including four municipalities with provincial status and five autonomous regions) has two political leaders: provincial secretary and provincial governor. The former is the head of the provincial branch of the Communist Party, and the latter is the head of the provincial government. Provincial secretaries are ranked equally to ministers in the central government, and ranked higher than provincial governors. By "provincial leaders", we mean either of these two political leaders in each province.

Provincial leaders in China have a large discretion over economic policies at the provincial level while their career prospects are controlled by the central government. ${ }^{9}$ Provincial economic performance, specifically real GDP growth, is considered to be a performance measure highly relevant to the PSC's promotion decision (Maskin, Qian, and Xu 2000; Blancher and Shleifer 2001).

Promoted provincial leaders may join the Politburo of the Communist Party (the second most powerful decision-making body after the PSC) and/or become Vice-premier or State Councilor, the highest positions in the central government after the Premier. In other words, promoted provincial leaders become close colleagues of the PSC members. Promoting political enemies may thus threaten the power of the PSC members.

\section{A Simple Model}

This section proposes a simple theoretical framework to illustrate three empirically-testable mechanisms through which the interplay of connections and performance emerges in the promotion decision for Chinese provincial leaders. We employ a simplified version of the standard career concern model (Holmström 1982) to formalize the promotion process as

\footnotetext{
${ }^{9} \mathrm{Xu}(2011)$ refers to this institutional feature as a regionally decentralized authoritarian system. Although it is interesting to study the coordination and competition between secretaries and governors, we leave this to future research.
} 
a screening device with the PSC as the unitary decision-maker. In this framework, we incorporate three potential roles of social connections discussed in the literature. First, connections may foster loyalty of provincial leaders to PSC members, implying that the probability of the PSC to survive in office is higher if the PSC promotes a connected provincial leader. The literature on Chinese politics (e.g. Dittmer 1995) argues that Chinese political leaders build a network of loyal followers to reduce the uncertainty of their political survival. We call this first role of connections loyalty-fostering.

The second and third roles of connections are both informational. Connections may provide PSC members with two types of information: the ability of provincial leaders and the economic conditions of the province they rule. The literature on social connections in labor markets (see Ioannides and Loury 2004 for a review) often assumes that connections mitigate asymmetric information on the ability of potential employees or that information flows through connections. It is plausible that PSC members know the ability of their connected provincial leaders better than that of those unconnected. We call this second role of connections ability-learning. It is also likely that PSC members communicate more often with their connected provincial leaders and that such interactions transmit the information on the provincial economy over and above its GDP growth rate. We call this third role of connections communication-enhancing.

Our model shows that complementarity between connections and performance arises when connections play the loyalty-fostering or communication-enhancing role. Connections and performance are substitutes when connections play the ability-learning role. In Section 5 , we report evidence for the complementarity of connections and performance. In Section 6 , we then provide further evidence that the complementarity appears to be driven by the loyalty-fostering role of connections rather than the communication-enhancing role.

Other mechanisms may also explain complementarity or substitutability of connections and performance. We discuss these in section 3.3.

\subsection{Model}

Consider a simplified version of the standard career-concern model, where the PSC is the only strategic player and unitarily decides whether or not to promote a provincial leader. For simplicity, provincial leaders are assumed to be non-strategic: we do not consider their effortmaking to boost growth. As we show in the Appendix Section A.2, the theoretical results are mostly robust to a strategic provincial leader whose effort affects provincial growth as in the standard career-concern model.

The PSC derives its utility from the rent obtained by being in office and the ability of the promoted provincial leader $i$, denoted by $R$ and $a_{i}$, respectively. For simplicity, we assume the following functional form:

$$
u\left(R, a_{i}\right)=R+\eta a_{i}
$$


where parameter $\eta$ measures the extent to which the PSC prefers promoting an official with higher ability (i.e. meritocracy).

Ability, $a_{i}$, is assumed to be unobservable to the PSC. However, provincial economic growth since $i$ starts ruling the province, denoted by $g_{i}$, is observed and determined by:

$$
g_{i}=a_{i}+\varepsilon_{i}
$$

where $\varepsilon_{i}$ is a stochastic shock affecting economic growth beyond $i$ 's control.

We now introduce three roles of connections into this framework. Let $C_{i} \in\{0,1\}$ be an indicator that takes the value of one if $i$ is connected to the PSC and zero otherwise.

Loyalty-fostering The loyalty-fostering role of connections assumes that the probability for the PSC of staying in power depends on $C_{i}$, where this probability, denoted by $p\left(C_{i}\right)$, satisfies $p(1)>p(0)$. Unconnected officials are more likely to attempt to oust other PSC members than connected ones, if they are promoted.

Ability-learning The first informational role of connections, ability-learning, works through the variance of $a_{i}$. We assume that the ex ante distribution of $a_{i}$ is known to be normal with mean $\bar{a}$ and variance $\sigma_{a}\left(C_{i}\right) .{ }^{10}$ Moreover, connections equip the PSC with more precise information on the ability of provincial leader $i$, implied by $\sigma_{a}(1)<\sigma_{a}(0)$.

Communication-enhancing The second informational role of connections, communicationenhancing, works through the variance of $\varepsilon_{i}$. We assume that $\varepsilon_{i}$ is known to be normally distributed with mean zero and variance $\sigma_{\varepsilon}(0)$. Connections allow the PSC to learn more about the economic conditions of $i$ 's province, hence $\sigma_{\varepsilon}(1)<\sigma_{\varepsilon}(0)$.

The expected utility of the PSC from promoting $i$ with connection status $C_{i}$ and growth performance $g_{i}$, which we denote by $W_{i}^{C_{i}}$, is then written as follows:

$$
W_{i}^{C_{i}} \equiv E\left[u\left(R, a_{i}\right) \mid g_{i}\right]=p\left(C_{i}\right)\left[R+\eta E\left(a_{i} \mid g_{i}\right)\right]
$$

where we normalize the payoff of being ousted from office to zero.

If the PSC does not promote $i$, its payoff is given by $\bar{u}$, which may represent the payoff of promoting the most able official in the central government or leaving the high-office position vacant. Provincial leader $i$ is promoted if $W_{i}^{C_{i}} \geq \bar{u}$. Assuming that $\bar{u}$ is distributed by the cumulative density function $F(\bar{u})$, the probability of promotion for $i$ is $F\left(W_{i}^{C_{i}}\right)$. For simplicity, we assume that $\bar{u}$ is uniformly distributed with the probability density $\mu .^{11}$

\footnotetext{
${ }^{10}$ As discussed below, allowing connections to affect the mean ability does not change the nature of the interaction between connections and performance in determining the promotion probability.

${ }^{11}$ As shown in Appendix Section A.2, the functional form for $F(\bar{u})$ does not affect our main theoretical result, Proposition 1 below, as long as the observed growth rate, $g_{i}$, does not take extreme values and $p(1) / p(0)$ sufficiently differs from $h(0) / h(1)$ (see below for the definition of $h\left(C_{i}\right)$ ).
} 
Before we proceed to the analysis of this model, a few of its assumptions merit discussions here. First, the loyalty-fostering role of connections takes the form of increasing the PSC's probability of survival, instead of directly entering into the PSC's payoff. This assumption reflects not only the possibility of coup d'état but also that of pro-democracy political reforms advocated by party officials. The introduction of multiparty democracy, for example, will reduce the probability of staying in power for the Communist Party, and thus the PSC. It is plausible that connected officials are unlikely to push ahead policies that threaten the power of their connected senior officials. However, it is usually difficult for researchers to directly observe loyalty. In Appendix Section A.1, we discuss two cases during two critical moments in modern China's history that may shed light on how connections affect loyalty. The first case shows the loyalty of Li Zuopeng to his patron Lin Biao in the political struggle between Lin and Mao Zedong. The second case discusses how the disagreement between Zhao Ziyang and Deng Xiaoping in the Tiananmen square protests might be related to the fact that Zhao was promoted on the basis of ability.

Second, we assume that the provincial leader's ability affects the economic growth of the province he rules. This assumption reflects the fact that provincial leaders have a large discretion over economic policies at their province, as mentioned in Section 2. In Section 7, we also provide supporting evidence that, among those officials who serve provincial leadership for more than one spell, the provincial economic growth during their second term is positively correlated with that during their first term.

Finally, we assume that the PSC cares about the ability of promoted officials only when the PSC remains in power. It implies that the PSC members prefer promoting more talented officials because working with such colleagues reduces the disutility from running the government. Our model does not assume that the PSC members benevolently prefer a higher quality of government. If so, they would care about the ability even after leaving office.

\subsection{Analysis}

From equation (2) and the distributional assumptions on $a_{i}$ and $\varepsilon_{i}, E\left(a_{i} \mid g_{i}\right)$ is given by the weighted average of $g_{i}$ and $\bar{a}$ with the weights being the relative precision of growth and ability:

$$
E\left(a_{i} \mid g_{i}\right)=h\left(C_{i}\right) g_{i}+\left(1-h\left(C_{i}\right)\right) \bar{a},
$$

where

$$
h\left(C_{i}\right) \equiv \frac{\sigma_{a}\left(C_{i}\right)}{\sigma_{a}\left(C_{i}\right)+\sigma_{\varepsilon}\left(C_{i}\right)} .
$$

Note that $h\left(C_{i}\right)$ is increasing in $\sigma_{a}\left(C_{i}\right)$ and decreasing in $\sigma_{\varepsilon}\left(C_{i}\right)$. If the main informational role of connections is ability-learning, we have $h(0)>h(1)$. If the communication-enhancing role of connections dominates, we have $h(0)<h(1)$.

Hence, the marginal increase in the promotion probability with respect to economic 
growth $g_{i}$ is:

$$
\frac{\partial F\left(W_{i}^{C_{i}}\right)}{\partial g_{i}}=\mu \eta p\left(C_{i}\right) h\left(C_{i}\right) .
$$

If this expression is larger for $C_{i}=1$ than for $C_{i}=0$, connections and growth complement each other in increasing the promotion probability. If it is smaller for $C_{i}=1$, connections and growth are substitutes. If it is the same irrespective of $C_{i}$, the effects of connections and growth on promotion are independent of each other.

Inspecting Equation (5) yields the following proposition.

Proposition 1. The effects of connections and growth on promotion are:

\section{Independent if}

(a) $\eta=0$ or $h\left(C_{i}\right)=0$ (i.e. $\sigma_{\varepsilon}\left(C_{i}\right)=\infty$ ). In this case, provincial growth does not affect the promotion probability, and the PSC is more likely to promote connected officials as long as $p(1)>p(0)$.

(b) $\eta>0, h\left(C_{i}\right)>0$, but $p(1) h(1)=p(0) h(0)$. In this razors-edge case, the promotion probability increases with growth, but not with connections.

2. Complementary if $\eta>0$ and

$$
\frac{p(1)}{p(0)}>\frac{h(0)}{h(1)}
$$

3. Substitutes if $\eta>0$ and

$$
\frac{p(1)}{p(0)}<\frac{h(0)}{h(1)}
$$

Proof. Substitution of parameter conditions into expression (5) and comparison between $C_{i}=1$ and $C_{i}=0$ trivially prove the statements in the proposition.

Proposition 1 shows that the interplay of connections and growth in affecting the promotion probability requires three conditions: (1) the PSC cares about the ability of promoted officials, (2) provincial growth contains a signal on the ability of provincial leaders, and (3) connections play at least one of the three roles specified in this model. ${ }^{12}$

The proposition also shows which type of roles of connections lead to complementarity or substitutability of connections and performance. If the loyalty-fostering role of connections (represented by $p(1) / p(0)$ ) is large enough, the complementarity arises. On the other hand, the informational roles of connections lead to the substitutability if the ability-learning role

\footnotetext{
${ }^{12}$ In the unlikely case in which the loyalty-fostering role of connections exactly cancels the informational roles of connections to satisfy $p(1) h(1)=p(0) h(0)$, the interdependency of connections and growth disappears (case 1 (b) in the Proposition).
} 
dominates (i.e. $h(0) / h(1)$ is large enough due to $\sigma_{a}(1)<\sigma_{a}(0)$ ), and to the complementarity if the communication-enhancing role dominates (i.e. $h(0) / h(1)$ is small enough due to $\sigma_{\varepsilon}(1)<$ $\sigma_{\varepsilon}(0)$.

The Appendix Section A.2 discusses several extensions of the above model. First of all, the probability of staying in office, $p\left(C_{i}\right)$, may decrease in $a_{i}$ if competent officials threaten the survival of top leaders. ${ }^{13}$ On the other hand, connections may mitigate this threat by fostering loyalty. In this case, a similar result to Proposition 1 holds as long as $g_{i}$ does not take extreme values and, if $h(0)>h(1), h(0) / h(1)$ is sufficiently smaller than $p(1) / p(0)$.

Second, provincial leader $i$ may be able to boost the economic growth of his province by exerting effort (as in a standard career-concern model). As long as ability and effort affect growth additively, however, such strategic behavior of provincial leaders does not alter our result.

Finally, average ability, $\bar{a}$, for example, may depend on $C_{i}$. Connected provincial leaders may have a higher $\bar{a}$ if the PSC can screen out less able candidates for provincial leadership positions among those connected. However, as expression (5) does not contain $\bar{a}$, allowing connections to influence $\bar{a}$ does not change the above result. ${ }^{14}$

In summary, the above analysis shows that the effects of connections and growth on promotion can be intertwined, an insight that has been ignored in the previous literature. In the empirical analysis to follow, we investigate whether the promotion probability indeed responds to the interaction of connections and growth.

\subsection{Discussion}

Other mechanisms may also explain the complementarity (or substitutability) of connections and performance. First of all, while in our model promotion plays a role of screening, the literature on the career of Chinese provincial leaders often emphasizes the role of promotion as an incentive scheme for provincial leaders to boost economic growth (e.g. Maskin et al. 2000). In the Appendix Section A.3, we show that a model of promotion as an incentive scheme predicts the interdependence of connections and performance as long as the PSC can commit to the promotion scheme, which may be a strong assumption (Fairburn and Malcomson 2001).

Second, connections may play an informational role in a different sense. The PSC members may be too busy to spend a lot of time deciding who to promote. Consequently they may pay more attention to connected provincial leaders than unconnected ones. This attention-creating role of connections would also predict the complementarity of connections and growth. Although our empirical analysis cannot completely exclude this possibility,

\footnotetext{
${ }^{13}$ Egorov and Sonin (2011) argue that the tradeoff between loyalty and ability creates a dilemma for the dictator when choosing high officials. See also Besley et al. (2012) in the context of the choice of electoral lists by political party leaders in Sweden.

${ }^{14}$ For general distribution functions of $\bar{u}$, the result is robust as long as $p(1) / p(0)$ is sufficiently larger or smaller than $h(0) / h(1)$ and $g_{i}$ does not take extreme values. See Appendix Section A.2.
} 
we believe that it is unlikely. Promoted provincial leaders will assume top positions in the central government. The PSC members should thus spend enough time to consider all the candidates for these top positions, including those not connected to them, to select the best officials. If the PSC ignores unconnected provincial leaders, it is likely to be because the lack of connections involves the lack of desirable qualities such as loyalty.

Third, the interplay of connections and performance can also emerge from a model in which the PSC's preference is additive in the ability of the promoted official and the direct benefit from having a connected colleague (altruism to connected people or the joy of working with friends, for example). If the threshold for promotion is high due to a small number of vacant positions, this model predicts complementarity because either high ability or connectedness alone is not enough to pass the threshold. If the threshold for promotion is low, on the other hand, the model predicts substitutability. Due to the lack of sufficient variation in the number of vacant positions in our data, we cannot empirically test this possibility.

Finally, in our model, the PSC is assumed to be the unitary actor. Bargaining among PSC members with conflicting interests may also yield complementarity or substitutability of connections and performance. Empirically, this mechanism is difficult to test. We know very little about the actual bargaining process of the PSC. In addition, during the sample period of our data (1993-2009), the membership composition of the PSC only changed three times, not enough to test the implications of a bargaining model. We leave the testing of this interesting hypothesis to future research.

\section{Data and Empirical Strategy}

Our main data source is China Vitae (2012), a website run by a non-profit organization in the United States. It publishes curriculum vitae (CV) of Chinese Communist Party officials who have held important positions since late 1992. The CV includes the year of birth, the province of birth, colleges attended, and, most importantly, the list of positions held in the party or in the government (including state-owned enterprises) in the past, along with the period in which each position was held.

We first explain how our sample of provincial leaders is selected and then explain how we use their CV to measure promotion and connections. We also discuss the data on provincial economic growth and present summary statistics. After presenting the data, we explain our main empirical strategy.

\subsection{Sample}

We focus on provincial secretaries and governors, who hold office for at least twelve months in between June 1993 and June 2009. ${ }^{15}$ There are 275 provincial leadership spells (137

\footnotetext{
${ }^{15}$ We start from 1993 because China Vitae (2012) does not cover officials in office in June 1992 or before. Our sample period ends in 2009 as annual growth data is available up to 2009 when the first draft of this
} 
secretaries and 138 governors) that satisfy these criteria. From this set of spells, we drop 17 (seven secretaries and ten governors) whose CV is not available in China Vitae (2012). ${ }^{16}$ Since some officials assume a provincial leadership position more than once, the total number of officials in the sample is 187, less than the 258 observed leadership spells.

\subsection{Promotion}

We define the promotion of provincial leaders in the least controversial way. We regard a provincial secretary as promoted if he becomes a member of the Politburo (the second highest decision-making body in the Communist Party, consisting of 20 to 25 members that include all members of the PSC), a Vice-Premier or a State Councilor in the central government. ${ }^{17}$ A provincial governor is promoted if he becomes a secretary of the same or a different province. There is no instance where a provincial governor joins the Politburo or becomes a Vice-Premier or a State Councilor.

Assuming other positions in the central government such as vice-chairmanship of the Chinese parliaments (National People's Congress and Chinese People's Political Consultative Conference) and, for governors, the head of a ministry could perhaps also be seen as promotion (see Tao et al. 2010). In Appendix Section A.4, we find that our results are robust to these wider definitions of promotion, suggesting that our findings are not dependent on a particular way of measuring promotions

\subsection{Connections}

We measure the connection between a pair of party officials by whether they used to work in the same branch of the Party or of the government at the same time. In particular, we focus on links between each provincial leader and any current member of the PSC, given that the PSC is in charge of the decisions on the promotion of provincial leaders. ${ }^{18}$ The connection indicator can thus change for the same provincial leader if his connected PSC member resigns or if his connected official joins the PSC. ${ }^{19}$ In our sample period, we find

paper was written. We look at June because, following Li and Zhou (2005), we measure the promotion outcome during the period between July of year $t$ and June of year $t+1$, which is to be matched with economic growth in year $t$. Finally, we drop provincial leaders whose tenure is less than twelve months because the promotion of such leaders is unlikely to be associated with annual provincial growth.

${ }^{16}$ There is little attrition bias in terms of provincial economic growth: the difference in the average annual provincial growth since assuming office is 0.7 percentage points (not statistically different from zero), $6 \%$ of the whole sample mean, between provincial leaders with and without an available CV, conditional on province and year fixed effects.

${ }^{17}$ Some provincial secretaries join the Politburo without leaving office. If this happens, we record this as their promotion and treat the rest of the leadership spell as a separate one. There are three such cases. When a provincial secretary with the Politburo membership leaves office, joining the PSC is defined as promotion.

${ }^{18}$ In Section 5.2, we also consider links between each provincial leader and any current non-StandingCommittee members of the Politburo.

${ }^{19}$ Potentially we can exploit this within-individual variation to identify the impact of connections, as in Jia (2012), because membership changes in the PSC are plausibly exogenous. Out of 187 officials in the 
that connections between PSC members and provincial leaders are mostly formed at the provincial branches of the Party and of the government, but also at central bodies such as ministries, the National People's Congress and the Communist Youth League. ${ }^{20}$

The number of connections is at most two in our data. Below we briefly look at how promotion patterns differ by the number of connections.

The focus on workplace-based connections among Chinese politicians is motivated by the anecdotes mentioned in footnote 4: General Secretaries promoted their former colleagues once they assumed power. However, the literature on informal politics in China (see Dittmer 1995, for example) also points out the importance of other sources of connections among politicians, such as graduating from the same college or hailing from the same province. In Section 5.4 we investigate whether these alternative sources of connections are also of importance.

An estimation of the effect of connections defined in this way should be seen as an "intention-to-treat" analysis, using the language of the program-evaluation literature. Having worked together in the past does not necessarily mean being loyal to each other, well informed about each other's ability, or frequently in touch. However, it is plausible that having worked together increases the probability of being loyal to, familiar with, and/or in close contact with each other. As a result, if we do not find connections significantly correlated with promotion, we should not interpret this to say that connections are unimportant.

\subsection{Economic Growth}

The data on provincial annual real GDP growth up to year 2009 is obtained from the National Bureau of Statistics of China (2009, 2011).

One may question the reliability of the provincial GDP growth data, given the possibility that higher growth increases the chance of promotion for top provincial politicians. The central government of China ensures the reliability of provincial GDP data in two ways. ${ }^{21}$ First, each provincial government is required to submit the figures for various subcomponents of GDP. The National Bureau of Statistics (NBS) in the central government then doublechecks the total GDP figure by aggregating these subcomponents on its own. Second, the NBS conducts its own survey to obtain its own estimates of provincial GDP. Therefore, even though provincial leaders may have an incentive to overreport the growth of their provincial

data, however, only 25 change their connection status during their tenure. When we estimate the stratified Cox proportional hazard model where the stratum is each individual (so we can control for unobserved heterogeneity across individuals), we obtain inconclusive results with very large standard errors.

${ }^{20}$ We also find that the difference in position ranks for connected pairs (each position of the Party and the government has an official rank) is usually no more than two when they worked together. To make our coding procedure tractable, we disregard the periods of working at a local government below the provincial level from each official's curriculum vitae. Consequently, an official working for a prefectural or county government is not regarded as connected to another working for a provincial government in which the prefecture or county is located.

${ }^{21}$ We thank Li-An Zhou for providing us with this information. 
economy, the provincial GDP data should reflect the actual performance of the economy to a large extent. ${ }^{22}$

Our empirical analysis below controls for province and year fixed effects so that the difference in the extent of over-reporting across provinces and across years does not affect our results. More serious is the concern that the extent to which provincial leaders overreport provincial GDP growth differs by their connection status. Our analysis below deals with this concern in three ways. First, connected provincial leaders do not necessarily report higher growth than unconnected ones, as shown in the bar graph of Figure 2 below. Second, among connected provincial leaders, growth is not significantly different by the observable strength of connections, as shown in Section 5.3. Thus, it is unlikely that only provincial leaders who are strongly connected can overreport growth. Finally, if connected provincial leaders report growth more accurately than unconnected ones, we would observe the complementarity of connections and performance due to the communication-enhancing role of connections. In Section 6.2, we provide evidence against this mechanism.

\subsection{Summary Statistics}

Column 1 of Table 1 reports summary statistics for the variables used in the following analysis at the level of 258 leadership spells. Columns 2 and 3 restrict the sample to provincial secretaries and governors, respectively. About a quarter of the provincial leadership spells end with promotion. The promotion rate is lower for secretaries, consistent with the fact that secretaries are more highly ranked than governors in the Communist Party hierarchy. The share of spells with the provincial leader connected to PSC members for at least one year is about a quarter, with a slightly higher share for secretaries. The mean of average annual provincial real GDP growth since assuming office is around eleven percentage points. Each leadership spell lasts 4.3 years on average, consistent with the fact that the Communist Party makes major personnel decisions every five years when the Party Congress is held.

In the empirical analysis below, we construct a leader-year level sample in which each leadership spell is observed annually until the leader is transferred to another position, irrespective of whether it is a promotion or not. This process results in 966 observations. The summary statistics for this sample are reported in column 4 of Table 1.

Figure 1 shows the rate of promotion (the line graph) and the distribution of tenure length (the bar graph) by the number of years in office. It shows that the chance of promotion

\footnotetext{
${ }^{22}$ We corroborate the quality of the provincial growth data by checking if it reflects the growth in nighttime lights observed by satellites. Nighttime lights can be seen as an objective measure of living standards, and therefore its correlation with GDP is indicative of the quality of GDP data. Using data on nighttime lights from National Geophysical Data Center (2010) and on Chinese provincial boundaries form Natural Earth (2012), we follow Henderson et al. (2012) in measuring and aggregating nighttime lights to the provincial level. The correlation coefficient (conditional on province and year fixed effects) between annual GDP growth and annual light growth is about 0.1 , significantly different from zero at the $5 \%$ level. This evidence suggests that real GDP growth, at least to some extent, reflects improvements in some dimensions of living standards captured by nighttime lights.
} 
increases until the fifth year in office and declines thereafter. The peak at five years is expected, since many of the personnel decisions are made at the National Congress of the Communist Party which is held every five years. The figure also shows that the majority of leadership spells ends in five years or less.

\subsection{Empirical Strategy}

The structure of the leader-year level data suggests using a competing risks model, in which observations exit from the data through more than one type of event (promotion and nonpromotional transfer in our case). However, below we treat non-promotional transfers as right-censoring by assuming that non-promotional transfers occurs randomly. Furthermore, we use a linear probability model of promotion, instead of a Cox proportional hazard model, by assuming that the duration of each leadership spell does not depend on connection status and growth. Although these assumptions are restrictive, the linear probability model allows us to control for unobservable heterogeneity across provinces and years that can differ between secretaries and governors, which we believe is important in our context to minimize the bias in the estimation.

Therefore, to investigate how the promotion of provincial leaders is correlated with their connections and performance, we estimate the following linear probability model:

$$
\begin{aligned}
P_{i o p t}= & \alpha C_{i t}+\beta\left(G_{i o p t}-\bar{G}\right)+\gamma C_{i t} *\left(G_{i o p t}-\bar{G}\right) \\
& +\boldsymbol{x}_{i o p t}^{\prime} \boldsymbol{\delta}+\left(G_{i o p t}-\bar{G}\right) * \boldsymbol{x}_{\text {iopt }}^{\prime} \boldsymbol{\xi}+\sum_{\tau=2}^{12} \kappa_{\tau} T_{i o p t}^{\tau}+\mu_{o p}+\eta_{o t}+\varepsilon_{i o p t}
\end{aligned}
$$

The dependent variable, $P_{\text {iopt }}$, is the indicator that takes the value of one if provincial leader $i$ in office $o$ (secretary or governor) in province $p$ is promoted in the period from July of year $t$ to June of year $t+1 .^{23}$ We have three regressors of interest. The first is $C_{i t}$, the indicator of leader $i$ being connected to the members of the PSC in office in June of year $t$. The second is $G_{\text {iopt }}$, the average annual growth rate of province $p$ since leader $i$ assumed office $o$ until year $t$, measured as the deviation from the sample mean, $\bar{G}(11.4 \%)$. The last is the interaction term of these two variables. To facilitate the interpretation of the coefficient on the connection indicator, $\alpha$, the growth variable is demeaned so that $\alpha$ measures the difference in the probability of promotion between connected and unconnected officials displaying average growth performance. For robustness checks, we control for $\boldsymbol{x}_{i o p t}$, a vector of characteristics of provincial leader $i$ and province $p$ in year $t$, and its interaction with $\left(G_{i o p t}-\bar{G}\right)$, to investigate whether the endogeneity of $C_{i t}$ is driving our main results.

Province and year fixed effects are allowed to differ between secretaries and governors $\left(\mu_{o p}\right.$ and $\left.\eta_{o t}\right)$. Controlling for province fixed effects ensures that the coefficients of interest $(\alpha, \beta, \gamma)$ do not pick up the possibilities that certain provinces which grow more quickly

\footnotetext{
${ }^{23}$ See footnote 15 for why we measure promotion during the period from July.
} 
also have their leaders more likely promoted and connected. Controlling for year fixed effects incorporates the possibility of relative performance evaluation, often discussed in the literature on Chinese political selection (e.g. Maskin et al. 2000, Chen et al. 2005). It also allows for higher promotion rates in Party Congress years, in which many personnel decisions are made.

Since the promotion probability changes non-linearly with the number of years in office, as suggested by Figure 1, we also control for a set of dummies for the number of years in office from two to twelve $\left(T_{\text {iopt }}^{\tau}\right){ }^{24}$

Standard errors are clustered at the province level given that both growth rates, $G_{\text {iopt }}$ and the error term are likely to be serially correlated within each province, and $C_{i t}$ tends to take the same value for the same province for a certain number of years. As the low number of Chinese provinces (31) may cause an underestimation of the standard errors, even with clustering, we also report $p$-values on the significance of the estimated $\gamma$ by using the wild cluster bootstrap-t procedure (Cameron et al. 2008).

The coefficient on the interaction term of connections and growth, $\gamma$, is negative if the two determinants of promotion are substitutes and is positive if they are complements.

\section{$5 \quad$ Evidence for Complementarity between Connections and Performance}

We present evidence for the complementarity of connections and performance in three steps. First, we show our baseline estimates. Second, we discuss the endogeneity concerns of connections. Third, we discuss whether provincial economic growth is a good measure of the provincial leader's performance. We also briefly remark on other sources of connections.

\subsection{Baseline Estimates}

Table 2 shows our main results from estimating equation (8). The first three columns estimate the correlations of promotion with connections and growth without introducing their interaction term, thus making them directly comparable to the previous studies. Column 1 shows that connected provincial leaders are more likely to be promoted. The difference is estimated at 4.9 percentage points - nearly $60 \%$ of the average promotion rate - and statistically significant at the $5 \%$ level. This finding confirms anecdotal pieces of evidence mentioned in the introduction. It is also in line with recent evidence by political scientists (Shih et al. 2012). In column 2, we find that the promotion probability increases with the provincial economic growth during the tenure, although it is not significantly different from zero. The point estimate suggests that a one standard deviation increase in growth (by 2.4 percentage points) pushes up the probability of promotion by 1.7 percentage points. This

\footnotetext{
${ }^{24}$ These dummies may be endogenous. However, the results do not differ significantly if we do not control for these dummies.
} 
magnitude is comparable to the one estimated by Li and Zhou (2005). ${ }^{25}$ Column 3 includes both the connection indicator and provincial GDP growth as regressors. The results are similar to those in the previous columns, suggesting that the connection status is largely orthogonal to provincial GDP growth once province and year fixed effects are controlled for.

Column 4 presents our key finding by including the interaction term of connections and growth as a regressor. The coefficient on the interaction term is positive and statistically significant at the $5 \%$ level (or at the $10 \%$ level if we use the p-value by Cameron et al. (2008)), suggesting that the two determinants of promotion are complements rather than substitutes. The point estimate indicates that a one standard deviation increase in growth raises the promotion probability by 5.3 percentage points more for connected officials than for unconnected ones. The coefficient on the connection indicator suggests that the promotion rate for provincial leaders with the sample average growth is 3.2 percentage points higher for those connected than for those unconnected, although this difference is not statistically significant. The growth effect for unconnected officials is insignificant although the point estimate suggests that a one standard deviation increase in growth increases the probability of promotion by 0.8 percentage points, which is more than $10 \%$ of the sample mean promotion rate.

Since unobservable heterogeneity may differ between connected and unconnected provincial leaders, we also estimate equation (8) separately for those connected and unconnected, after dropping the connection indicator and its interaction term with growth from the right hand side. Appendix Table A.1 reports the results. The correlation is clearly larger for connected provincial leaders than for unconnected ones. ${ }^{26}$

Some provincial leaders have two connections instead of one. Appendix Table A.2 sees if the complementarity between connections and performance differs by the number of connections. The point estimates suggest that the degree of complementarity increases with the number of connections. However, since only about one-fourth of connected leader-year observations have two connections, the standard error is too large to be conclusive.

Figure 2 shows our main result graphically. We first regress both the promotion dummy and provincial growth since assuming office on dummies of the numbers of years in office, province-office fixed effects, and year-office fixed effects, and obtain the residuals from these regressions. Then, we divide the observations into tertiles according to the residual growth, irrespective of connection status. ${ }^{27}$ Finally, for each tertile, we plot the average residual promotion rate by connection status. We also use the bar graph in the background to show the distribution of connected observations across growth tertiles.

The figure shows that the complementary result is entirely driven by a large difference in

${ }^{25}$ The result of Li and Zhou (2005) suggests that a one standard deviation increase in growth raises the promotion probability by 1.8 percentage points.

${ }^{26}$ To see whether the difference in the size of the coefficients on growth is statistically significant, we also estimate (8) with all the fixed effects and the number-of-year-in-office dummies interacted with the connection indicator. The coefficient on the connection-growth interaction term is significant at the $5 \%$ level (the wild cluster bootstrap-t $p$-value is 0.068 ).

${ }^{27}$ We obtain similar results when we divide observations into quintile. 
the promotion rates between connected and unconnected provincial leaders among the topthird of growth performers. For unconnected provincial leaders, the worst third performers are slightly less likely to be promoted than the rest. In terms of the distribution of growth performances, connected officials are most likely to be in the middle tertile, but do not disproportionately perform better or worse than their unconnected peers.

Our key finding implies that the previous literature fails to recognize the importance of the interplay between connections and growth in determining the promotion of provincial leaders, and perhaps of Chinese Communist Party officials in general. Connected officials do have a higher likelihood of promotion on average, but this is solely due to their promotion probability being more responsive to performance. Put differently, officials with a better performance appear to be promoted more often, but this relationship mainly applies to those connected to top political leaders of China.

In terms of the theoretical framework introduced in Section 3, our results suggest that connections either foster loyalty of provincial leaders to top leaders or enhance communication between them, instead of providing the PSC members with information about the provincial leader's ability.

\subsection{Discussions of the Connection Measure}

The connection status of provincial leaders may be endogenous to their promotion probability. Below we consider four major concerns one by one.

Individual Characteristics Connected provincial leaders may be different from unconnected ones in terms of their individual characteristics, and these differences may affect their promotion chance. Besides basic demographic variables (age and education), we look at whether provincial leaders have served in the central government before assuming provincial leadership, and whether they rule their native province. Connected provincial leaders may be on the elite career track which includes positions in the central government and various provinces while unconnected ones may rule their native province only. We also look at whether they are princelings, the sons or sons-in-law of prominent Communist Party officials. Princelings are known to form a powerful faction within the Communist Party. ${ }^{28}$ Connections to the PSC members may simply reflect the political advantage of being a princeling.

Table 3 compares the means of observable characteristics of provincial leadership spells between the connected and unconnected, where connection status is measured at the first year of the spell (as changes in connection status during the tenure are due to membership reshuffling of the PSC and thus more likely to be exogenous). Columns 1 to 3 report unconditional mean differences while column 4 reports the estimated coefficient on the connection indicator

\footnotetext{
${ }^{28}$ The data on princelings come from China Vitae (2012). Xi Jinping, General Secretary since 2012, is a princeling. The media often reported factional struggles between princelings and the former members of the Communist Youth League headed by the outgoing General Secretary Hu Jintao in the lead-up to the 2012 Party Congress.
} 
from regressing each of these variables on the connection indicator, office-by-province fixed effects, and office-by-year (where the year refers to when each leader assumes office, ranging from 1983 to 2009) fixed effects. Panel A reports differences in individual characteristics. While having graduated from college and being a princeling do not differ significantly, connected officials are significantly younger, more likely to have served in the central government, and less likely to be serving the home province. Except for ruling the home province, these differences persist even after taking into account unobservable differences across province and time.

In columns 5 and 6 of Table 2, we estimate equation (8) where the control variable vector, $\boldsymbol{x}_{i o p t}$, includes age and the indicator of having served in the central government, respectively. Note that age is measured at the time when assuming office, and is thus time-invariant for each leadership spell. In both columns, the estimated coefficients on the connection indicator and its interaction term with growth change little from the estimates in column 4 .

In Appendix Section A.4, we also control for the other individual characteristics (the indicators of graduating from college, ruling the home province, and being a princeling) and their interactions with growth. The estimated complementarity of connections and growth is remarkably stable across all these different specifications.

Taken together, the above pieces of evidence suggest that our main finding is not driven by observable differences in individual characteristics of provincial leaders.

Assignment of Provinces Connected officials may be assigned to a particular set of provinces. First, they may systematically rule provinces growing faster or slower than the rest. If the growth performance of a province, either good or bad, indicates its importance for the central government, our connection measure may reflect ruling politically important provinces, rather than actual connections. Growth in such provinces may be more likely to be rewarded with promotion. If connected leaders are systematically assigned to slowgrowing provinces, our connection measure simply reflects the difficulty in achieving high growth. The complementarity then arises because growth for such provinces is a stronger signal of the ability of the provincial leader.

To deal with these concerns, we measure the provincial growth over the five-year period before each provincial leadership spell begins. Panel B of Table 3 shows that the provinces ruled by connected officials are more likely to have higher previous growth. However, this difference is insignificant once we control for province and time fixed effects. In Appendix Section A.4, we show that controlling for the previous growth and its interaction with growth (during the tenure) does not change our main result.

The second set of concerns is that connected provincial leaders may be assigned to provinces that PSC members have a great deal of knowledge about. If this is the case, growth is a stronger signal of the official's ability, thus explaining the stronger responsiveness of the promotion rate to growth.

To measure this feature, we use two variables: an indicator of provinces where current members of the PSC used to work, and an indicator of provinces where the current mem- 
bers of the PSC were born. Panel B of Table 3 shows that while the PSC home province indicator is not significantly different, connected officials are significantly more likely to rule the province where the PSC members used to work, even conditional on province and time fixed effects. In column 7 of Table 2, we control for the PSC's former workplace province indicator and its interaction with growth. The estimated coefficients on the connection indicator and its interaction term with growth change little from the estimates in column 4 . In Appendix Section A.4, we show that controlling for the PSC home province indicator and its interaction with growth does not change our main result.

In summary, the above evidence shows that systematic observable differences in the assignment of provinces between connected and unconnected officials, if any, do not explain the complementarity of connections and performance.

Support from the Central Government The third concern on our measure of connections is that it may reflect how much support provincial leaders obtain from the central government due to their connection status to the PSC members. PSC members may help connected provincial leaders achieve high growth so that they can promote them as if the decision were based on meritocracy. To deal with this concern, we consider three dimensions of the central government's support to provinces. First, as an explicit transfer to provinces, we look at fiscal transfers from the center to each provincial government annually since 1994 (China Financial \& Economic Publishing House, various years). Second, as an implicit transfer to provinces, we follow Shih $(2004,2008)$ and use the annual data on the loan-to-deposit ratio (National Bureau of Statistics of China 2009) as a measure of credit market intervention by the central government (major banks in China are all state-owned). Third, as a policy measure of support to provinces, for each province we obtain an annual increase in the number of municipalities with the Special Economic Zone (SEZ) status from the municipality-level data complied by Wang (2012). ${ }^{29}$ For each of these three measures, we focus on the average over each leadership spell.

Panel C of Table 2 reports the difference in these averages between connected and unconnected provincial leaders. An unconditional comparison suggests that connected provincial leaders do obtain significantly more fiscal transfers from the central government, less bank loans, and (insignificantly) less SEZ permissions. But, once we take into account province and year fixed effects, this difference is no longer significantly different from zero (column 4). These results suggest that the connection indicator does not reflect more support from the central government to boost provincial growth, conditional on differences across provinces and across years.

\footnotetext{
${ }^{29}$ The SEZ is an area with more liberal laws and economic policies to encourage foreign direct investment for export. It is the central government that authorizes local governments to establish SEZs. Wang (2012) provides empirical evidence that SEZs indeed increased foreign direct investment, exports, and total factor productivity growth. Note that this data drops four provincial-level municipalities (Beijing, Shanghai, Tianjin, and Chongqing) from the sample. Since the number of municipalities differs across provinces, we also use the indicator of having at least one municipality become an SEZ or the share of new SEZs to the total number of municipalities, yielding similar results.
} 
Being the Political Elite The fourth concern is that connections may simply reflect being a member of China's political elite. A certain set of workplaces may be the home of every top leader in China. As a result, those destined for promotion have worked with the current top leaders in the PSC, and this has nothing to do with social connections between PSC members and provincial leaders.

Table 5 checks this possibility. In column 1, we include a measure of connection between provincial leaders and past or future PSC members rather than current members. In column 2 , we instead add an indicator for provincial leaders who used to work in the same place as current PSC members but in a different period. They should thus pick up the effect of the elite status, but not of connections. These dummies are set to zero if our main connection indicator is one. Therefore, the coefficients on these variables and their interaction with growth will be the same as those on the connection indicator if connections simply reflected the elite status.

Table 5 shows that the coefficients on these additional regressors are not significantly different from zero. The F-test rejects the null that the effect of being connected to the current members of the PSC is the same as that of being connected to the past or future members of the PSC (column 1) or of working in the same place as current PSC members in a different period (column 2) at the 5\% and 10\% levels, respectively. The result in column 1 also suggests that our connection indicator does not reflect being trained on the job by a mentor who would later join the PSC.

In column 3, we look at the impact of being connected to current members of the Politburo, the second highest decision-making body in the Communist Party. Connections to the PSC members may simply reflect connections to top politicians in general. If so, connections to the Politburo should also be of importance. However, coefficients on the Politburo connection indicator (set to be zero if the PSC connection indicator is one) and its interaction with growth are not significantly different from zero, and the F-test rejects the equality of these coefficients to those for PSC connections at the $5 \%$ level.

All these results in Table 5 imply that connections to the people with decision-making power count the most. Consequently, the estimated correlation of connections with promotion is driven by whether the provincial leader's connections are the members of the PSC, which is plausibly beyond each provincial leader's control.

\subsection{Is Growth a Performance Measure?}

The provincial GDP growth data may not reflect the performance on basis of which the promotion decision is taken. For example, provincial growth may be higher for those who are promised promotion, because the central government offers support to them to boost economic growth of their province so that their promotion will look merit-based. If so, we should see a significant drop in economic growth in the province after its leader has been promoted. Columns 1 and 2 of Table 4 investigate this issue. With balanced panel data of provinces for 1993-2009, we regress annual real GDP growth on indicators for one, two, and 
three years after promotion as well as on province and year fixed effects. These indicators are defined based on the promotion of provincial secretaries in column 1 and governors in column 2. The estimated coefficients on these indicators are, however, insignificant and positive in most cases.

Provincial growth may also reflect the strength of connections. Our measure of connections does not necessarily reflect the actual connections. PSC members may provide support to boost the economy only to those provincial leaders who are actually connected to them. Although we cannot entirely dismiss this possibility, we can use observable characteristics of connections that may be correlated with the strength of connections, to check if real GDP growth is higher for provinces whose leader's connection to the PSC is stronger. Columns 3 to 6 of Table 4 run provincial panel regressions of the following form:

$$
g_{p t}=\phi C_{p t}+\xi C_{p t} * Z_{p t}+\psi_{p}+\omega_{t}+\varepsilon_{p t},
$$

where $g_{p t}$ is the annual real GDP growth of province $p$ in year $t, C_{p t}$ the indicator that the leader in province $p$ in year $t$ is connected to the PSC member(s), $Z_{p t}$ the strength of connections of the leader in province $p$ in year $t, \psi_{p}$ the province fixed effect, and $\omega_{t}$ the year fixed effects. We use two variables to measure $Z_{p t}$. First, we measure the number of years that the provincial leader has worked together with his connected PSC member(s), assuming that a longer time together strengthens connections. ${ }^{30}$ Second, we take the difference in ages between the connected pair by subtracting the age of the provincial leader from that of the PSC member, assuming that a larger age difference strengthens connections. Different generations of party officials do not compete with each other for power due to the seniority system of promotion. ${ }^{31}$ We run this regression separately for provincial secretaries and provincial governors, the former reported in columns 3-4 and the latter in 5-6.

Columns 3 and 5 measure the strength of connections by the number of years working together. While this interaction term is insignificant for provincial secretaries, growth is significantly higher for provincial governors whose connection is stronger by this measure. Plotting the data reveals one outlier (Fujian in 1993) where the governor has worked with a PSC member for 14 years (the maximum in the sample) and the provincial economy grew by $22.6 \%$, almost twice the sample mean. If we drop this observation, the interaction term in column 5 becomes insignificant. Our main results in Table 2 are immune to this outlier, either. $^{32}$

Columns 4 and 6 use the age difference variable (which is positive if the provincial leader is younger than his connected PSC members) as a measure of the strength of connections. Its

\footnotetext{
${ }^{30}$ If the provincial leader has more than one connection, we take the average. The results do not substantially change if we take the maximum or the minimum.

${ }^{31}$ It might also be the case that the connections are stronger if the connected pair of individuals is more similar in age. To reflect this possibility, we also measure the age difference in absolute value. The results are similar.

${ }^{32}$ The coefficient on the interaction of connection and growth for column 4 of Table 2 is reduced by one-fifth in size, but it remains significant at the $5 \%$ level.
} 
interaction term with the connection indicator is insignificant both for provincial secretaries and governors. ${ }^{33}$

These results suggest that provincial growth is not higher for those provincial leaders whose connections may be stronger in terms of observable dimensions, encouraging the interpretation of growth as a performance measure, rather than a measure of the strength of connections.

\subsection{Other Connection Sources}

In Appendix Section A.5, we also investigate whether other sources of social connections are of importance for promotion. We do not find any significant effects of connections from sharing the college to graduate or the province of birth. Sharing working experience seems to be of greater importance than sharing the same birthplace or knowing each other via the college alumni network. Another interpretation of these results is that our measures of school and birth place connections are coarser than those based on shared working experience.

\section{Evidence for the Loyalty-fostering Role of Connec- tions}

In light of our theoretical framework in Section 3, the empirical evidence presented in the previous section is consistent with two roles of connections: loyalty-fostering and communicationenhancing. In this section, we attempt to empirically disentangle these two roles by investigating heterogeneity in the degree of complementarity along two dimensions: the age difference between the provincial leader and his connected PSC member and the length of tenure of provincial leaders.

\subsection{Age Difference}

Since the 1990s, the Communist Party of China has undergone generational changes of leadership every ten years. Older party officials tend to have more power than junior ones while officials in similar ages compete with each other for high office. Thus, it is plausible that provincial leaders show more loyalty towards connected PSC members whose age is higher than their own. Consequently, if the complementarity between connections and performance in the promotion process is due to the loyalty-fostering role of connections, we expect a stronger complementarity for the connected pairs in which provincial leaders are younger than the PSC members.

\footnotetext{
${ }^{33}$ Since the age difference is correlated with the provincial leader's own age, we also run regressions where we control for the age and its interaction with the connection indicator. The coefficients on the age difference interacted with the connection indicator remain insignificant.
} 
As in Section 5.3, we obtain the age difference between provincial leaders and their connected PSC members by subtracting the age of the provincial leader from that of the PSC member. ${ }^{34}$ In our sample, provincial leaders are on average 7.1 years younger than their connected PSC members, with a standard deviation of 5.8 years. We include the interactions of this variable with the connection indicator and with the connection-growth interaction term as two additional regressors to equation (8). If the age difference makes the complementarity of connections and growth stronger, the coefficient on its interaction with the connection-growth interaction term will be positive.

Column 1 in Table 6 reports the results from this estimation. It shows that the complementarity between connections and performance are indeed stronger for pairs where provincial leaders are younger than their connected PSC members. A one standard deviation larger age difference raises the coefficient on the interaction between connections and growth by 1.44. ${ }^{35}$ These results are consistent with the hypothesis that the complementarity between connections and performance is due to the loyalty-fostering role of connections.

\subsection{Tenure}

In Appendix Section A.6, we extend the theoretical framework in Section 3 to a case where the economic growth rate of $i$ 's province is observed annually during $i$ 's rule. We show that, as long as growth is as much informative about $i$ 's true ability as the prior mean ability, the degree of complementarity decreases with each provincial leader's tenure if the complementarity of connections and performance is (at least partly) driven by the communicationenhancing role of connections. ${ }^{36}$ Provincial economic growth becomes a more accurate signal of the true ability of provincial leaders when it is observed over more years. Thus, a longer tenure diminishes the communication advantage of connections between the PSC and the provincial leader.

We test this prediction empirically. As Figure 1 shows, we do not observe any promotion after the 9 th year in office. Therefore, we censor tenure by converting the 9 th year or later into the 8th year. We then interact this variable with growth, the connection indicator, and their interaction term. Note that the dummies for the number of years in office have always been controlled for.

Column 2 in Table 6 reports the results from this estimation. While being insignificant,

\footnotetext{
${ }^{34}$ If there are two connected PSC members, we take the maximum.

${ }^{35}$ As this result may be driven by the provincial leader's own age, independent of the PSC member's age, we check the robustness to controlling for the provincial leader's age when he assumed office (the same variable as the one used in column 5 of Table 2) and its interactions with the connection indicator, growth, and the connection-growth interaction term. The size of the coefficient on the age difference interacted with the connection-growth interaction term becomes smaller and insignificant ( 0.174 with the standard error of 0.141) while the age interacted with the connection-growth interaction term is negative but insignificant. Variation in our data is not enough to be conclusive about whether the age difference or the age of provincial leaders per se matters.

${ }^{36}$ More specifically, as long as $\sigma_{\varepsilon}(0) \sigma_{\varepsilon}(1)$ is not too large relative to $\sigma_{a}(0) \sigma_{a}(1)$, the difference in equation (5) between $C_{i}=1$ and $C_{i}=0$ decreases with the provincial leader $i$ 's ternure if $h(1)>h(0)$.
} 
the point estimate of the interaction term of connections, growth, and tenure is positive. This means that the complementarity between connections and performance are, if anything, stronger for those provincial leaders who have been in office for a longer period. This evidence contrasts with the theoretical prediction of the communication-enhancing role of connections.

Evidence in Table 6 thus supports the hypothesis that connections play a role of fostering loyalty of provincial leaders to PSC members.

\section{Implications on the Allocation of Talent}

What is the implication of our findings for the allocation of talent in the Chinese government? Unfortunately, we do not have any good measure of the ability of Chinese politicians once they leave the provincial leadership positions. However, we can look at provincial leaders with more than one spell: (1) secretaries and governors who get transferred to other provinces without promotion, (2) governors who are promoted and become secretaries of the same or a different province, and (3) secretaries who are promoted by joining the Politburo without leaving the provincial secretary office (see footnote 17). We observe the performance of these leaders after their promotion or non-promotional transfer. Again, it is measured by the real GDP growth of the new province in which they assume leadership. Despite being a selected sample of provincial leaders, analyzing this sample sheds some light on whether connected officials are more or less talented than unconnected ones, conditional on the initial performance.

This analysis can also provide suggestive evidence on whether provincial economic growth reflects the provincial leader's talent, as we assumed in Section 3, by checking if growth in the first term is positively correlated with growth in the second term. If economic growth is beyond the control of provincial leaders, we will not see such a correlation.

We first regress annual provincial real GDP growth on province and year fixed effects with the full balanced panel data of 31 provinces from 1993 to 2009, and calculate the residuals from this regression. Then, we estimate the following equation

$$
\hat{y}_{i}=\phi C_{i}+\xi\left(\hat{g}_{i}-\bar{g}\right)+\psi C_{i} *\left(\hat{g}_{i}-\bar{g}\right)+\omega_{i}
$$

where $\hat{y}_{i}$ is average conditional annual real GDP growth for official $i$ during his second term, $C_{i}$ the connection indicator in the last year of $i$ 's first term, $\hat{g}_{i}$ the average conditional annual real GDP growth for $i$ during his first term, and $\bar{g}$ the sample average of $\hat{g}_{i}$. A few officials also serve a third term. Such a case is treated as one additional observation for $i$ in our sample so that $\hat{y}_{i}$ refers to the third term and $C_{i}$ and $\hat{g}_{i}$ refer to the second term.

If $\phi \leq 0$ and $\psi<0$, connected officials with more than the average performance during the first term perform worse than unconnected ones with a similar first-term performance, indicating that the promotion pattern that we observe is inefficient. If $\phi \geq 0$ and $\psi \geq$ 0 , connected officials perform equally or better than unconnected ones if their first-term performance is more than the average, suggesting that promoting connected officials rather 
than unconnected ones among best performers may indeed be efficient.

In total, 58 officials serve more than one term of provincial leadership between 1993 and 2009, 13 of which serve three terms. In terms of leader-years, these officials account for 453 observations with a promotion probability of $12.4 \%$. This number is higher than that in the main sample $(7 \%)$ because part of the sample selection criteria requires the promotion from governors to secretaries and from secretaries to Politburo-member secretaries. In terms of performance and connections, this subsample is more or less comparable to the main sample, however. The average growth measured as the deviation from the whole sample average is 0.005 percentage points, and $18.1 \%$ of the leader-years are connected.

Column 1 of Table 7 replicates our main result by restricting the sample to leader-years served by these 58 officials. With this subsample, connected officials are significantly more likely to be promoted than those who are unconnected if their growth performance is average. For unconnected officials, higher growth reduces the promotion probability although this negative correlation is not significant. However, the complementarity between connection and growth does apply to this subset of provincial leaders.

Column 2 of Table 7 reports the result of estimating equation (9). Since first-term growth is demeaned, the coefficient on the connection indicator tells us the difference in the secondterm conditional growth between those connected and unconnected whose first-term growth is average, and it is not significantly different from zero. The higher the first-term growth, the higher is the second-term growth, with the coefficient being significant at the $10 \%$ level. The coefficient on the connection-growth interaction term is positive but not significantly different from zero.

The second-term growth might not reflect the ability. For example, it might be the case that good performers during the first term are rewarded by being assigned to a province that has been growing fast and therefore is easy to rule. For the 30 leadership spells that are followed by the transfer to another province, we check this possibility by estimating equation (9) with the dependent variable replaced with the average conditional growth of the second-term province during the period before the transfer. The result (not reported) shows that officials with higher first-term performance tend to be transferred to slower-growing provinces, with this relationship stronger for those connected.

Although not conclusive, these results suggest that promoting connected officials with high performance instead of unconnected ones with similarly high performance does not distort the allocation of talent in the Chinese government. In addition, the positive correlation of provincial economic growth between the first and second terms suggests that the ability of provincial leaders does appear to affect the economic performance of the province they rule. 


\section{Conclusions}

Our empirical analysis shows a robustly stronger positive correlation of the province's economic growth and its ruler's promotion chance for those connected to top politicians in the central government of China than for those not connected. Although other mechanisms may explain this empirical pattern, we propose, and provide evidence consistent with, one plausible explanation: connections foster loyalty of junior officials to senior ones, allowing the incumbent top politicians to promote the most able ones among those connected.

Political selection in autocracy often involves a trade-off between competence and loyalty (Egorov and Sonin 2011). Appointing competent officials to high office threatens the power of an autocrat. As a result, incompetent but loyal subordinates tend to surround the autocrat, which is one contributing factor to a poor quality of government in autocracy.

Our evidence might suggest how China has avoided this trap. A system of job rotation and promotion within the Communist Party helps pairs of officials build trust by working together. Within a pool of officials with such connections, top officials are then able to pick the most talented without being threatened. In this view, what we may call patronage or nepotism does not necessarily result in an inefficient allocation of talent.

\section{References}

[1] Acemoglu, Daron, Georgy Egorov, and Konstantin Sonin. 2010. "Political Selection and Persistence of Bad Governments." Quarterly Journal of Economics, 125(4): 1511-1575.

[2] Bertrand, Marianne, and Sendhil Mullainathan. 2001. "Are CEOs Rewarded for Luck? The Ones without Principals Are." Quarterly Journal of Economics, 116(3): 901-932.

[3] Besley, Timothy. 2005. "Political Selection." Journal of Economic Perspectives, 19(3): 43-60.

[4] Besley, Timothy, Olle Folke, Torsten Persson, and Johanna Rickne. 2012. "Gender Quotas and the Crisis of the Mediocre Man: Theory and Evidence from Sweden." Unpublished paper.

[5] Besley, Timothy, and Marta Reynal-Querol. 2011. "Do Democracies Select More Educated Leaders?" American Political Science Review, 105(03): 552-566.

[6] Blanchard, Olivier, and Andrei Shleifer. 2001. "Federalism With and Without Political Centralization: China Versus Russia." IMF Staff Papers, 48(4).

[7] Blanes i Vidal, Jordi, Mirko Draca, and Christian Fons-Rosen. 2012. "Revolving Door Lobbyists." American Economic Review, 102(7): 3731-3748.

[8] Bo, Zhiyue. 1996. "Economic Performance and Political Mobility: Chinese Provincial Leaders." Journal of Contemporary China, 5(12): 135-154. 
[9] Bo, Zhiyue. 2002. Chinese Provincial Leaders: Economic Performance and Political Mobility Since 1949. Armonk, New York: M.E. Sharpe.

[10] Cameron, A. Colin, Jonah B. Gelbach, and Douglas L. Miller. 2008. "Bootstrap-based Improvements for Inference with Clustered Errors." Review of Economics 85 Statistics, 90(3): 414-427.

[11] Caselli, Francesco, and Massimo Morelli. 2004. "Bad Politicians." Journal of Public Economics, 88: 759-782.

[12] Chen, Ye, Hongbin Li, and Li-An Zhou. 2005. "Relative Performance Evaluation and the Turnover of Provincial Leaders in China." Economics Letters, 88: 421-425.

[13] China Financial \& Economic Publishing House, various years. Various years. Finance Yearbook of China. Various issues. Beijing: China Financial \& Economic Publishing House.

[14] China Vitae. 2012. China Vitae. www.chinavitae.com (accessed 17 February 2012).

[15] Dittmer, Lowell. 1995. "Chinese Informal Politics." China Journal, 34: 1-34.

[16] Edin, Maria. 2003. "State Capacity and Local Agent Control in China: CCP Cadre Management from a Township Perspective." China Quarterly, 173: 35-52.

[17] Egorov, Georgy, and Konstantin Sonin. 2011. "Dictators and Their Viziers: Endogenizing the Loyalty-competence Trade-off." Journal of the European Economic Association, 9(5): 903-930.

[18] Fairburn, James A., and James M. Malcomson. 2001. "Performance, Promotion, and the Peter Principle." Review of Economic Studies, 68(1): 45-66.

[19] Ferraz, Claudio, and Frederico Finan. 2011. "Motivating Politicians: The Impacts of Monetary Incentives on Quality and Performance." Unpublished paper.

[20] Francois, Patrick, Ilia Rainer, and Francesco Trebbi. 2012. "How Is Power Shared in Africa?" Unpublished paper.

[21] Fisman, Raymond. 2001. "Estimating the Value of Political Connections." American Economic Review, 91(4): 1095-1102.

[22] Galasso, Vincenzo, and Tommaso Nannicini. 2011. "Competing on Good Politicians." American Political Science Review, 105(01): 79-99.

[23] Garcia-Jimeno, Camilo, and James A Robinson. 2010. "Prosperity, Inequality, and Elites: The Determinants of Political Office-holding in Nineteenth Century Antioquia." In Colombian Economic History in the Nineteenth Century, eds. Adolfo Meisel and Maria Teresa Ramirez. Bogota: Fondo de Cultura Economica. 
[24] Henderson, J. Vernon, Adam Storeygard, and David N Weil. 2012. "Measuring Economic Growth from Outer Space." American Economic Review, 102(2): 994-1028.

[25] Holmström, Bengt. 1982. "Managerial Incentive Problems: A Dynamic Perspective", in Essays in Economics and Management in Honor of Lars Wahlbeck. Helsinki: Swedish School of Economics.

[26] Huang, Yasheng. 1998. "The Industrial Organization of Chinese Government." Harvard Business School Working Paper 99-076.

[27] Ioannides, Yannis M, and Linda Datcher Loury. 2004. "Job Information Networks, Neighborhood Effects, and Inequality." Journal of Economic Literature, 42(4): 1056-93.

[28] Jia, Ruixue. 2012. "Pollution for Promotion." Unpublished paper.

[29] Khwaja, Asim Ijaz, and Atif Mian. 2005. "Do Lenders Favor Politically Connected Firms? Rent Provision in an Emerging Financial Market." Quarterly Journal of Economics, 120(4): 1371-1411.

[30] Landry, Pierre F. 2008. Decentralized Authoritarianism in China. Cambridge University Press.

[31] Li, Danielle. 2013. "Expertise vs. Bias in Evaluation: Evidence from the NIH." Unpublished paper.

[32] Li, Hongbin, and Li-An Zhou. 2005. "Political Turnover and Economic Performance: the Incentive Role of Personnel Control in China." Journal of Public Economics, 89(9-10): 1743-1762.

[33] Li, Yinan. 2012. "China’s Political Business Cycle.” Unpublished paper.

[34] MacFarquhar, Roderick, and Michael Schoenhals (2009), Mao's Last Revolution, Harvard University Press.

[35] Maskin, Eric, Yingyi Qian, and Chenggang Xu. 2000. "Incentives, Information, and Organizational Form." Review of Economic Studies, 67: 359-378.

[36] Mattozzi, Andrea, and Antonio Merlo. 2008. "Political Careers or Career Politicians?" Journal of Public Economics, 92(3-4): 597-608.

[37] Mattozzi, Andrea, and Antonio Merlo. 2011. "Mediocracy." Unpublished paper.

[38] McGregor, Richard. 2010. The Party: The Secret World of China's Communist Rulers. HarperCollins Publishers.

[39] Messner, Matthias, and Mattias K. Polborn. 2004. "Paying Politicians." Journal of Public Economics, 88(12): 2423-2445. 
[40] Miller, Alice L. 2004. "Hu Jintao and the Party Politburo." China Leadership Monitor, 9. www.hoover.org/publications/china-leadership-monitor/article/6954 (accessed 1 June 2012).

[41] National Bureau of Statistics of China. 2009. Comprehensive Statistical Data and Materials for 60 Years of New China. Beijing: China Statistics Press.

[42] National Bureau of Statistics of China. 2011. China Statistical Yearbook 2010. Beijing: China Statistics Press.

[43] National Geophysical Data Center. 2010. DMSP-OLS Nighttime Lights Time Series (Version 4). National Oceanic and Atmospheric Administration. www.ngdc.noaa.gov/dmsp/downloadV4composites.html (accessed 20 January 2013).

[44] Natural Earth. 2012. 1:10m Cultural Vectors Admin 1 - States, Provinces. North American Cartographic Information Society. www.naturalearthdata.com (accessed 15 January 2013).

[45] Persson, Petra, and Ekaterina V. Zhuravskaya. 2012. "Elite Capture in the Absence of Democracy: Evidence from Backgrounds of Chinese Provincial Leaders." Unpublished paper.

[46] Shih, Victor. 2004. "Factions Matter: Personal Networks and the Distribution of Bank Loans in China." Journal of Contemporary China, 13(38): 3-19.

[47] Shih, Victor. 2008. Factions and Finance in China? Elite Conflict and Inflation. Cambridge: Cambridge University Press.

[48] Shih, Victor, Christoper Adolph and Mingxing Liu. 2012. "Getting Ahead in the Communist Party: Explaining the Advancement of Central Committee Members in China." American Political Science Review, 106: 166-187.

[49] Shirk, Susan. 1993. The Political Logic of Economic Reform in China. Berkeley: University of California Press.

[50] Tao, Ran, Fubing Su, Lu Xi and Yuming Zhu. 2010. "Jingjizengzhang nenggoudailai shengqian ma?: dui jinshengjinbiaojingsaililun de luojitiaozhan yu shengjishizhengchonggu (Does Economic Growth Lead to Promotion?: A Challenge of the Logic of Tournaments and A Reevaluation of the Provincial-level Data)." Guanlishijie (Management World), 12: 13-26.

[51] Whiting, Susan H. 2000. Power and Wealth in Rural China. Cambridge: Cambridge University Press. 
[52] Wong, Edward. 2012. "Family Ties and Hobnobbing Trump Merit at China Helm." New York Times, November 17, 2012. www.nytimes.com/2012/11/18/world/asia/familyties-and-hobnobbing-are-keys-to-power-in-china.html (accessed 7 February 2013).

[53] Xu, Chenggang. 2011. "The Fundamental Institutions of China's Reforms and Development." Journal of Economic Literature, 49(4): 1076-1151.

[54] Zhang, Weiwei. 2012. "Meritocracy Versus Democracy." New York Times, November 9, 2012. www.nytimes.com/2012/11/10/opinion/meritocracy-versus-democracy.html (accessed 7 February 2013). 


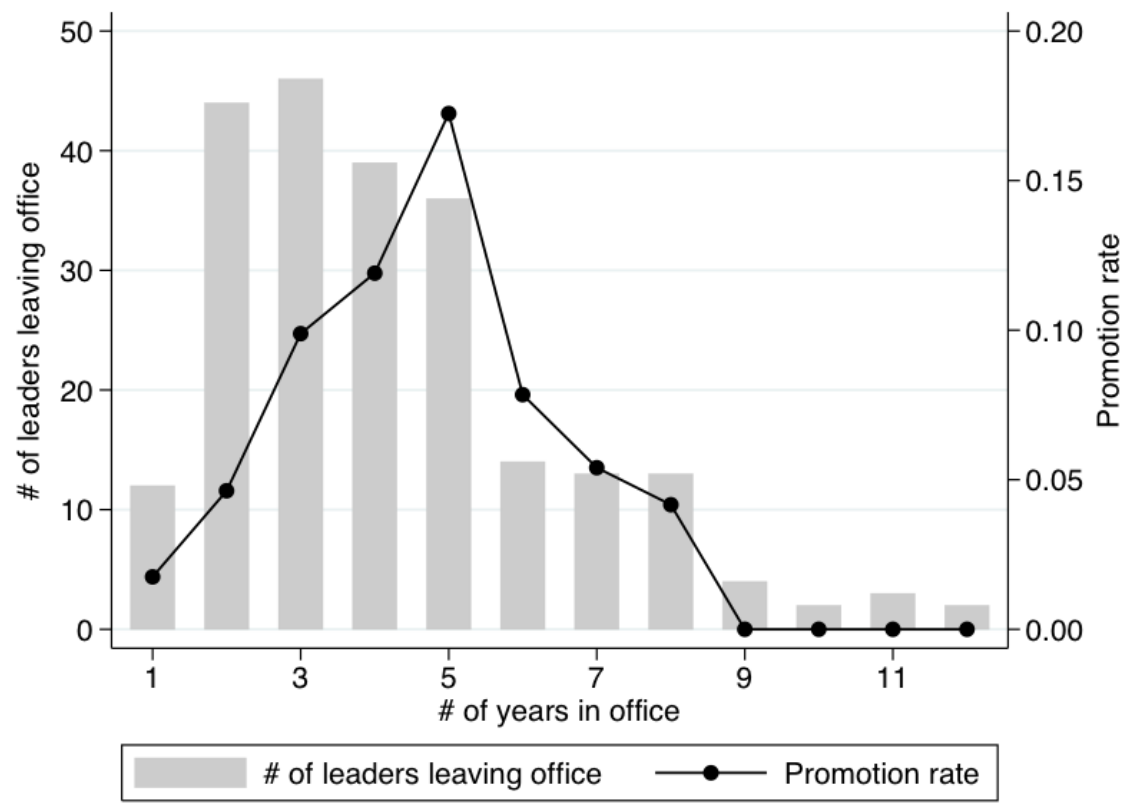

Figure 1: Distribution of term lengths and promotion rates by number of years in office Notes: See the text for how this graph is constructed.

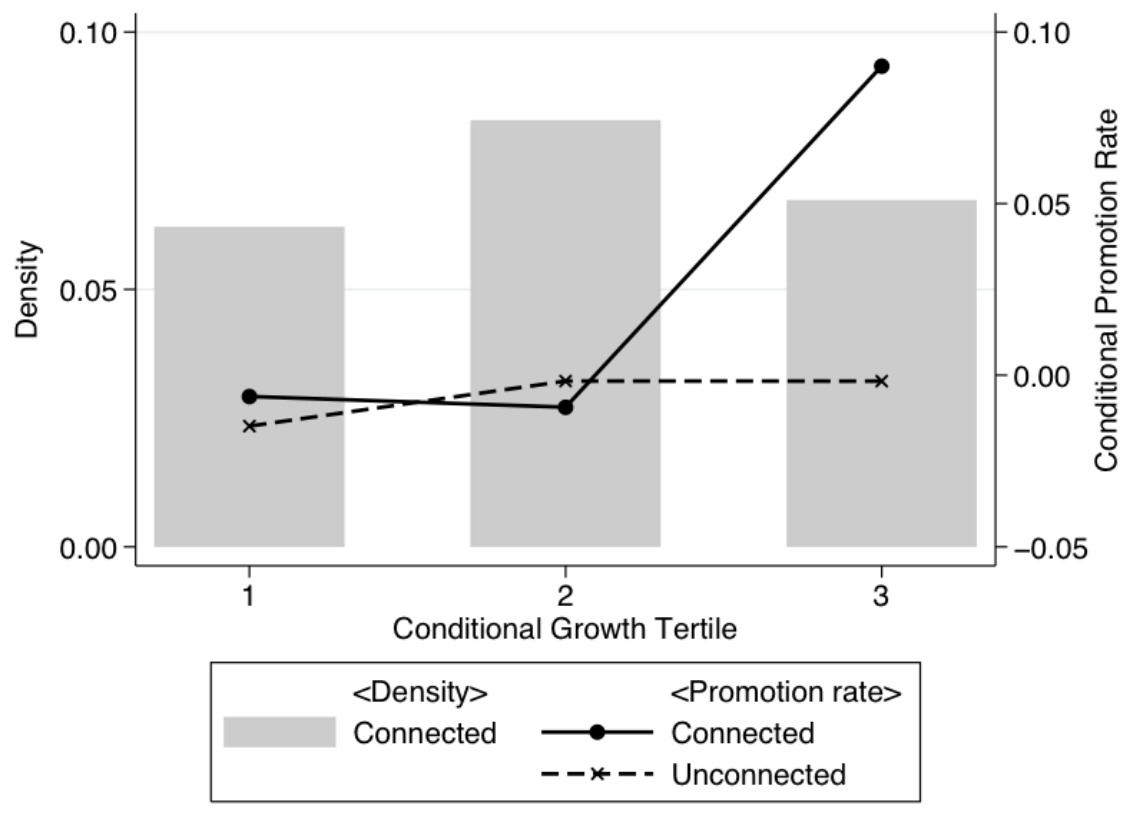

Figure 2: Promotion-growth relationship by connection

Notes: See the text for how this graph is constructed. 
Table 1: Descriptive statistics

\begin{tabular}{|c|c|c|c|c|}
\hline & $\begin{array}{c}(1) \\
\text { All } \\
\text { spells }\end{array}$ & $\begin{array}{c}(2) \\
\text { Secretary } \\
\text { spells }\end{array}$ & $\begin{array}{c}(3) \\
\text { Governor } \\
\text { spells }\end{array}$ & $\begin{array}{c}(4) \\
\text { Leader } \\
\text { years }\end{array}$ \\
\hline \multicolumn{5}{|l|}{ Measures of promotion } \\
\hline Promoted & 0.26 & 0.18 & 0.34 & 0.07 \\
\hline Minister & 0.29 & 0.18 & 0.40 & 0.08 \\
\hline $\mathrm{NPC}$ & 0.31 & 0.19 & 0.42 & 0.08 \\
\hline CPPCC & 0.33 & 0.22 & 0.45 & 0.09 \\
\hline \multicolumn{5}{|l|}{ Measures of connections } \\
\hline Connection & 0.25 & 0.27 & 0.23 & 0.21 \\
\hline Class & 0.07 & 0.07 & 0.07 & 0.05 \\
\hline Alumni & 0.12 & 0.13 & 0.11 & 0.10 \\
\hline Birth province & 0.41 & 0.44 & 0.39 & 0.36 \\
\hline Growth & $\begin{array}{c}0.11 \\
(0.02)\end{array}$ & $\begin{array}{c}0.11 \\
(0.02)\end{array}$ & $\begin{array}{c}0.11 \\
(0.02)\end{array}$ & $\begin{array}{c}0.11 \\
(0.02)\end{array}$ \\
\hline Term length & $\begin{array}{c}4.29 \\
(2.27)\end{array}$ & $\begin{array}{c}4.39 \\
(2.42)\end{array}$ & $\begin{array}{c}4.18 \\
(2.12)\end{array}$ & $\begin{array}{c}3.23 \\
(2.14)\end{array}$ \\
\hline \multicolumn{5}{|l|}{ Time-invariant covariates } \\
\hline Age & $\begin{array}{l}56.82 \\
(4.10)\end{array}$ & $\begin{array}{l}57.82 \\
(4.09)\end{array}$ & $\begin{array}{l}55.80 \\
(3.86)\end{array}$ & $\begin{array}{l}56.60 \\
(3.80)\end{array}$ \\
\hline Previous growth & $\begin{array}{c}0.11 \\
(0.02)\end{array}$ & $\begin{array}{c}0.11 \\
(0.02)\end{array}$ & $\begin{array}{c}0.11 \\
(0.03)\end{array}$ & $\begin{array}{c}0.11 \\
(0.02)\end{array}$ \\
\hline College graduate & 0.82 & 0.82 & 0.82 & 0.82 \\
\hline Served in center & 0.40 & 0.43 & 0.36 & 0.36 \\
\hline Home & 0.23 & 0.15 & 0.31 & 0.26 \\
\hline Princeling & 0.05 & 0.05 & 0.04 & 0.04 \\
\hline \multicolumn{5}{|l|}{ Time-variant covariates } \\
\hline PSC work province & 0.24 & 0.24 & 0.23 & 0.24 \\
\hline PSC home province & 0.26 & 0.25 & 0.28 & 0.22 \\
\hline Future/past connection & 0.21 & 0.22 & 0.21 & 0.18 \\
\hline Workplace & 0.31 & 0.35 & 0.27 & 0.24 \\
\hline Politburo connection & 0.27 & 0.27 & 0.27 & 0.21 \\
\hline Observations & 258 & 130 & 128 & 966 \\
\hline
\end{tabular}

Notes: Reported in each cell is the sample mean (and standard deviation in parentheses for continuous variables). The sample includes all leadership spells in column (1), provincial secretary spells in column (2), provincial governor spells in column (3) and leader-years in column (4). See Appendix Section A.7 for variable definitions. In columns (1)-(3), measures of promotion and Growth refer to the last year of the spell; measures of connections and time-variant covariates are the maximum value during the spell. 


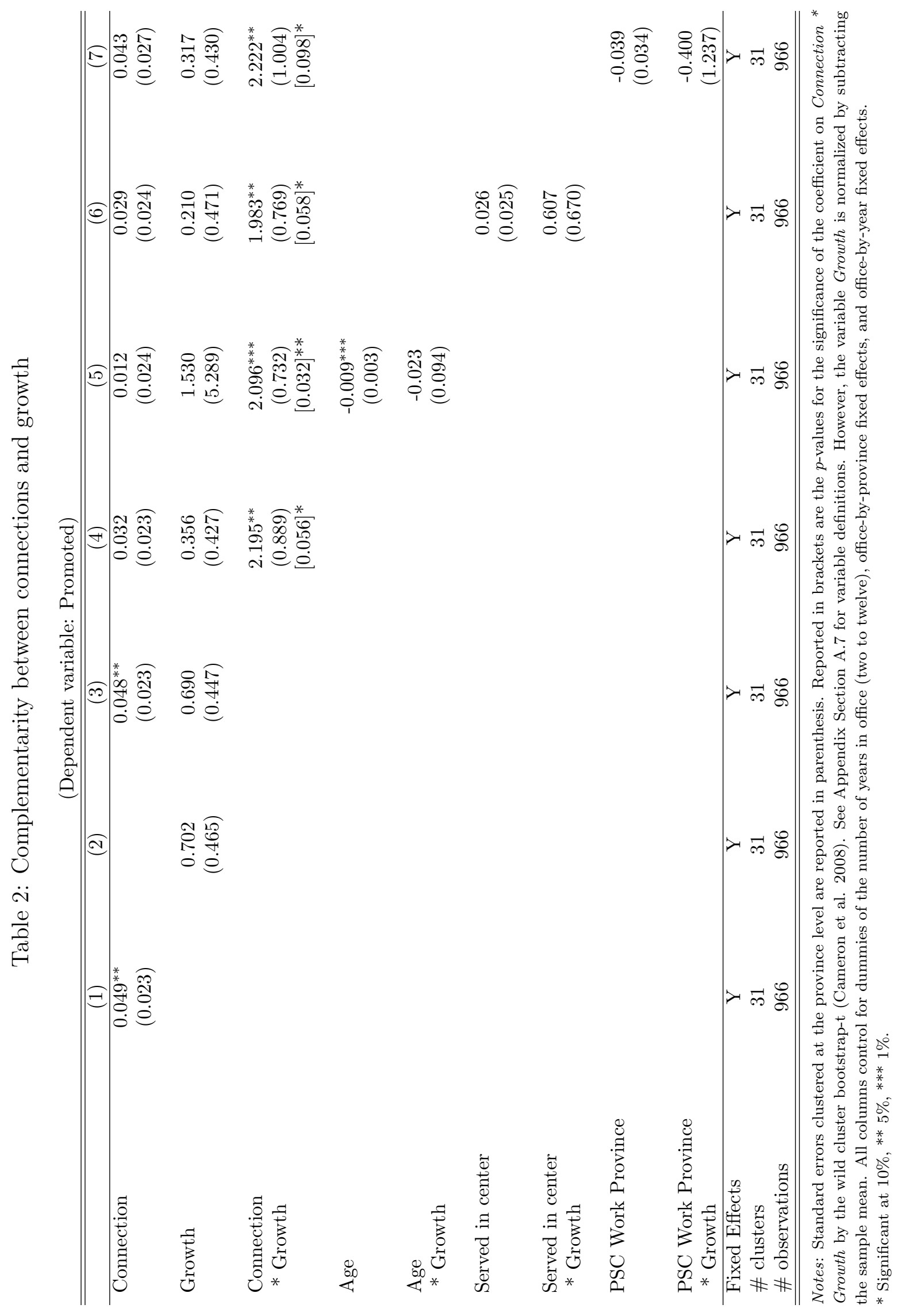


Table 3: Do connected leadership spells differ from unconnected ones?

\begin{tabular}{|c|c|c|c|c|}
\hline & $\begin{array}{c}(1) \\
\text { Connected }\end{array}$ & $\begin{array}{c}(2) \\
\text { Unconnected }\end{array}$ & $\begin{array}{c}(3) \\
t \text {-value }\end{array}$ & $\begin{array}{c}\text { (4) } \\
\text { Conditional difference }\end{array}$ \\
\hline \multicolumn{5}{|c|}{ Panel A: Provincial leader characteristics } \\
\hline Age & $\begin{array}{l}55.26 \\
(4.21)\end{array}$ & $\begin{array}{l}57.20 \\
(3.99)\end{array}$ & $-3.05^{* * *}$ & $\begin{array}{c}-3.35^{* * *} \\
{[0.88]}\end{array}$ \\
\hline College graduate & 0.88 & 0.82 & 1.27 & $\begin{array}{c}0.05 \\
{[0.07]}\end{array}$ \\
\hline Served in center & 0.53 & 0.37 & $2.35^{* *}$ & $\begin{array}{l}0.20^{*} \\
{[0.12]}\end{array}$ \\
\hline Home & 0.10 & 0.25 & $-2.43^{* *}$ & $\begin{array}{l}-0.06 \\
{[0.07]}\end{array}$ \\
\hline Princeling & 0.06 & 0.04 & 0.50 & $\begin{array}{l}0.00 \\
{[0.07]}\end{array}$ \\
\hline Observations & 50 & 208 & & 258 \\
\hline \multicolumn{5}{|c|}{ Panel B: Types of provinces assigned } \\
\hline Previous growth & $\begin{array}{c}0.12 \\
(0.02)\end{array}$ & $\begin{array}{c}0.10 \\
(0.03)\end{array}$ & $2.92^{* * *}$ & $\begin{array}{c}0.00 \\
{[0.00]}\end{array}$ \\
\hline PSC work province & 0.51 & 0.14 & $6.12^{* * *}$ & $\begin{array}{l}0.16^{*} \\
{[0.08]}\end{array}$ \\
\hline PSC home province & 0.29 & 0.22 & 0.88 & $\begin{array}{c}0.07 \\
{[0.07]}\end{array}$ \\
\hline Observations & 50 & 208 & & 258 \\
\hline \multicolumn{5}{|c|}{ Panel C: Central government support to provinces } \\
\hline $\begin{array}{l}\text { Transfer from center } \\
\text { (in million RMB) }\end{array}$ & $\begin{array}{c}4649.74 \\
(3855.64) \\
49\end{array}$ & $\begin{array}{c}3133.91 \\
(3280.62) \\
198\end{array}$ & $2.79^{* * *}$ & $\begin{array}{c}26.53 \\
{[507.86]} \\
247\end{array}$ \\
\hline $\begin{array}{l}\text { Loan to Deposit } \\
\text { Ratio }\end{array}$ & $\begin{array}{c}0.76 \\
(0.16) \\
50\end{array}$ & $\begin{array}{c}0.95 \\
(0.28) \\
207\end{array}$ & $-4.74^{* * *}$ & $\begin{array}{c}0.00 \\
{[0.03]} \\
257\end{array}$ \\
\hline $\begin{array}{r}\text { Number of } \\
\text { new SEZs }\end{array}$ & $\begin{array}{c}0.21 \\
(0.41) \\
34\end{array}$ & $\begin{array}{c}0.42 \\
(0.99) \\
185\end{array}$ & -1.25 & $\begin{array}{c}-0.01 \\
{[0.15]} \\
219\end{array}$ \\
\hline
\end{tabular}

Notes: The unit of observations is the leadership spell. Columns (1) and (2) report the mean (and standard deviation for continuous variables) for those spells where the provincial leader is connected and unconnected, respectively, to the PSC in the first year of the spell. Column (3) reports $t$-statistics for the null that the means in columns (1) and (2) are the same. Column (4) reports the estimated coefficient on the connection status in the first year of the spell (and robust standard errors in brackets) from a regression of each variable on the connection indicator, office-by-province dummies, and office-by-year dummies. In Panel C, the third row in each variable refers to the number of observations. See Appendix Section A.7 for variable definitions. To aggregate leader-year level data to the spell level, we take the first year observation for PSC work province and PSC home province.

$*$ Significant at $10 \%, * * 5 \%, * * * 1 \%$. 


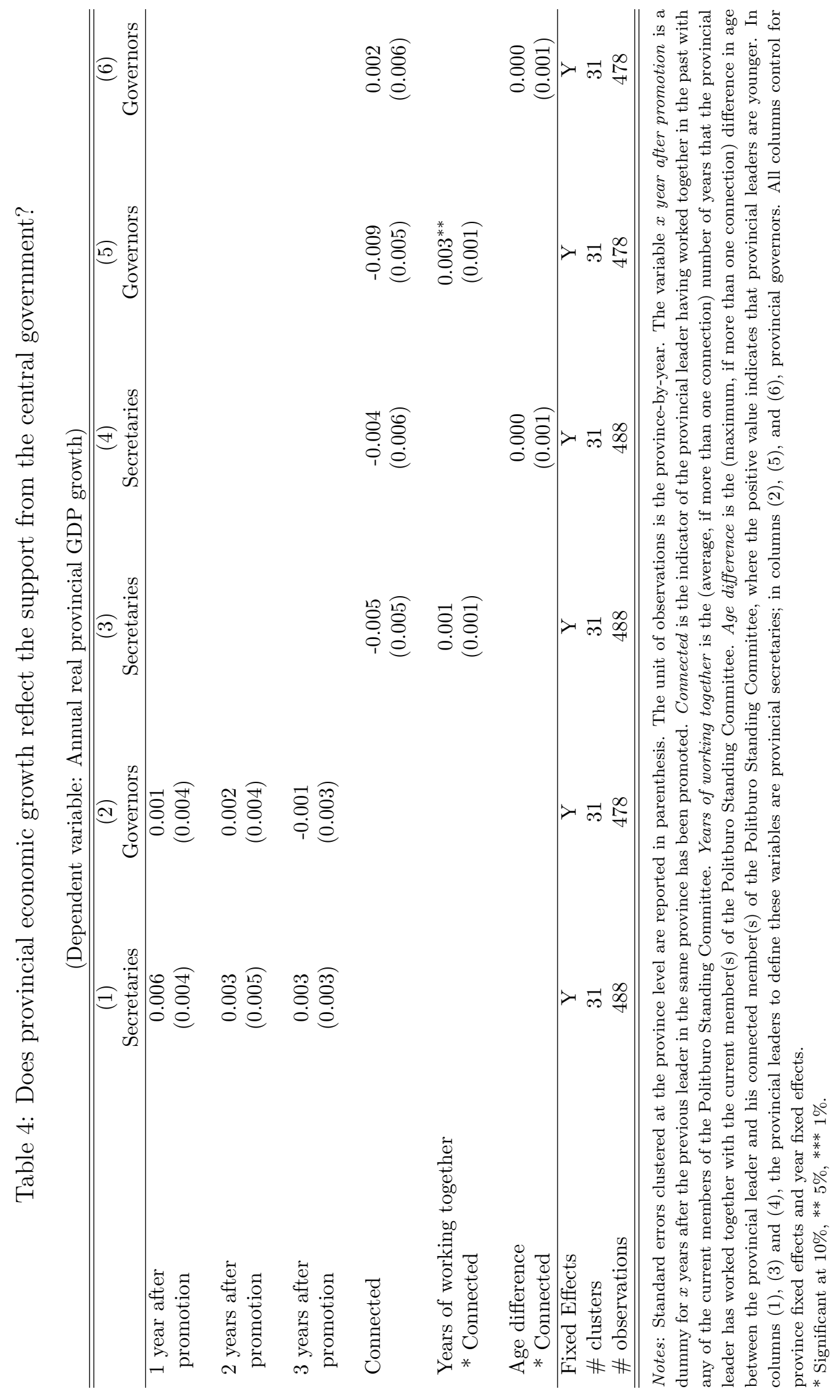


Table 5: Connections or being part of the political elite?

(Dependent variable: Promoted)

\begin{tabular}{|c|c|c|c|}
\hline & $\overline{(1)}$ & $\overline{(2)}$ & $\overline{(3)}$ \\
\hline Connection & $\begin{array}{c}0.033 \\
(0.028)\end{array}$ & $\begin{array}{l}0.043^{*} \\
(0.022)\end{array}$ & $\begin{array}{c}0.037 \\
(0.027)\end{array}$ \\
\hline Growth & $\begin{array}{c}0.414 \\
(0.483)\end{array}$ & $\begin{array}{c}0.234 \\
(0.507)\end{array}$ & $\begin{array}{c}0.395 \\
(0.479)\end{array}$ \\
\hline Connection $*$ Growth & $\begin{array}{c}2.125^{* *} \\
(0.938) \\
{[0.090]^{*}}\end{array}$ & $\begin{array}{c}2.351^{* *} \\
(0.902) \\
{[0.044]^{* *}}\end{array}$ & $\begin{array}{c}2.157^{* *} \\
(0.903) \\
{[0.058]^{*}}\end{array}$ \\
\hline Future/Past Connection & $\begin{array}{c}0.005 \\
(0.027)\end{array}$ & & \\
\hline Future/Past Connection * Growth & $\begin{array}{c}-0.265 \\
(1.059)\end{array}$ & & \\
\hline Workplace & & $\begin{array}{c}0.026 \\
(0.028)\end{array}$ & \\
\hline Workplace ${ }^{*}$ Growth & & $\begin{array}{c}0.285 \\
(0.742)\end{array}$ & \\
\hline Politburo Connection & & & $\begin{array}{c}0.013 \\
(0.019)\end{array}$ \\
\hline Politburo Connection * Growth & & & $\begin{array}{l}-0.234 \\
(0.653)\end{array}$ \\
\hline F-test & $\begin{array}{c}3.27 \\
{[0.052]^{*}}\end{array}$ & $\begin{array}{c}2.61 \\
{[0.090]^{*}}\end{array}$ & $\begin{array}{c}3.96 \\
{[0.030]^{* *}}\end{array}$ \\
\hline $\begin{array}{l}\text { Fixed Effects } \\
\text { \# clusters } \\
\text { \# observations }\end{array}$ & $\begin{array}{c}\mathrm{Y} \\
31 \\
966\end{array}$ & $\begin{array}{c}\mathrm{Y} \\
31 \\
966\end{array}$ & $\begin{array}{c}\mathrm{Y} \\
31 \\
966\end{array}$ \\
\hline
\end{tabular}

Notes: Standard errors clustered at the province level are reported in parenthesis. Reported in brackets are the $p$-values for the significance of the coefficient on Connection * Growth by wild cluster bootstrap-t (Cameron et al. 2008). See Appendix Section A.7 for variable definitions. However, the variable Growth is normalized by subtracting the sample mean. All columns control for dummies of the number of years in office (two to twelve), office-by-province fixed effects, and office-by-year fixed effects. $F$-test reports $F$-statistics and their associated $p$-values for the null that the coefficients on Connection and on Future/Past Connection in column (1), Workplace in column (2), or Politburo Connection in column (3), are the same and that the coefficients on their respective interaction terms with Growth are also the same.

$*$ Significant at $10 \%,{ }^{* *} 5 \%,{ }^{* * *} 1 \%$. 
Table 6: Heterogeneity in complementarity of connections and performance

(Dependent variable: Promoted)

\begin{tabular}{|c|c|c|}
\hline & $(1)$ & $(2)$ \\
\hline Connection & $\begin{array}{l}-0.004 \\
(0.026)\end{array}$ & $\begin{array}{c}0.000 \\
(0.037)\end{array}$ \\
\hline $\begin{array}{l}\text { Connection } \\
\text { *Age difference }\end{array}$ & $\begin{array}{l}0.005^{*} \\
(0.003)\end{array}$ & \\
\hline $\begin{array}{l}\text { Connection } \\
* \text { Tenure }\end{array}$ & & $\begin{array}{c}0.008 \\
(0.011)\end{array}$ \\
\hline Growth & $\begin{array}{c}0.295 \\
(0.446)\end{array}$ & $\begin{array}{c}0.031 \\
(0.668)\end{array}$ \\
\hline $\begin{array}{l}\text { Growth } \\
{ }^{*} \text { Tenure }\end{array}$ & & $\begin{array}{c}0.144 \\
(0.188)\end{array}$ \\
\hline $\begin{array}{l}\text { Connection } \\
* \text { Growth }\end{array}$ & $\begin{array}{c}0.310 \\
(0.992)\end{array}$ & $\begin{array}{l}-0.633 \\
(1.524)\end{array}$ \\
\hline $\begin{array}{l}\text { Connection } \\
* \text { Growth } \\
* \text { Age difference }\end{array}$ & $\begin{array}{c}0.247^{* *} \\
(0.102) \\
{[0.042]^{* *}}\end{array}$ & \\
\hline $\begin{array}{l}\text { Connection } \\
{ }^{*} \text { Growth } \\
\text { * Tenure }\end{array}$ & & $\begin{array}{l}1.314 \\
(0.798) \\
{[0.122]}\end{array}$ \\
\hline $\begin{array}{l}\text { Fixed Effects } \\
\text { \# clusters } \\
\# \text { observations }\end{array}$ & $\begin{array}{c}\mathrm{Y} \\
31 \\
966\end{array}$ & $\begin{array}{c}\mathrm{Y} \\
31 \\
966\end{array}$ \\
\hline
\end{tabular}

Notes: Standard errors clustered at the province level are reported in parenthesis. Reported in brackets are the $p$-values for the significance of the coefficient by wild cluster bootstrap-t (Cameron et al. 2008). Age difference is the (maximum, if more than one connections) difference in age between the provincial leader and his connected member(s) of the Politburo Standing Committee, where the positive value indicates that provincial leaders are younger. Tenure is the number of years in office with 9 years or longer being coded as 8 years. See Appendix Section A.7 for other variable definitions. However, the variable Growth is normalized by subtracting the sample mean. All columns control for dummies of the number of years in office (two to twelve), office-by-province fixed effects, and office-by-year fixed effects.

* Significant at $10 \%, * * 5 \%, * * * 1 \%$. 
Table 7: Implications on the allocation of talent

\begin{tabular}{lcc}
\hline \hline & $(1)$ & $(2)$ \\
Dependent variable: & Promoted & Second-term Growth \\
\hline Connection & $0.081^{* *}$ & 0.004 \\
& $(0.035)$ & $(0.004)$ \\
Growth & -0.309 & $0.162^{*}$ \\
& $(1.007)$ & $(0.094)$ \\
Connection ${ }^{*}$ Growth & $2.568^{*}$ & 0.167 \\
& $(1.352)$ & $(0.121)$ \\
\hline Observations & {$[0.140]$} & 71 \\
\hline \hline
\end{tabular}

Notes: In column (1), the unit of observations is the leader-year. The sample is restricted to those who assume provincial leadership positions more than once. The definition of variables is the same as in column 4 of Table 2. Standard errors clustered at the province level are reported in parenthesis. Reported in brackets is the $p$-value for the significance of the coefficient on Connection * Growth by wild cluster bootstrap-t (Cameron et al. 2008). Dummies of the number of years in office (two to twelve), office-by-province fixed effects, and office-by-year fixed effects are controlled for. In column (2), the leadership spell is the unit of observation. The sample is restricted to those who serve the second or third term of provincial leadership. The dependent variable is average annual growth during the tenure conditional on province and year fixed effects in a balanced province panel regression. Connection is an indicator of being connected in the last year of the previous term. Growth is the deviation of average conditional annual growth during the previous term from the sample average. No other variables are included as regressors. Robust standard errors are reported.

$*$ Significant at $10 \%,{ }^{* *} 5 \%, * * * 1 \%$. 


\section{A Appendix (Not for publication)}

\section{A.1 Cases of Connections and Loyalty}

Li Zuopeng in the Fall of Lin Biao in 1971 Li Zuopeng was a Lieutenant general with historical links to Lin Biao. They shared work histories at the Chinese People's AntiJapanese Military and Political University, where Li was a subordinate of Lin. After the success of the revolution, Li had steadily moved up the ranks under Lin's patronage and was appointed first political commissar of the navy in 1967 and promoted to Politburo at the First Plenum of the ninth CCP Central Committee (MacFarquhar and Schoenhals, 2009).

In the political struggle between Lin Biao and Mao Zedong, Li Zuopeng was a strong supporter of Lin Biao. After Lin's death and disgrace in 1971, Li Zuopeng admitted, "In life and in death, I would have stood by Vice Chairman Lin's side!" (MacFarquhar and Schoenhals, 2009). In 1980, Li was tried on charges of attempting to facilitate Lin's escape.

Zhao Ziyang and Tiananmen Square Protests of 1989 Our data analysis covers the period of 1993-2009. The decision-making process of the PSC during this period is likely to be deeply affected by what the Communist Party of China went through in 1989.37

In April, the death of $\mathrm{Hu}$ Yaobang triggered student demonstrations in Beijing. Hu was a popular official who had been removed from the position of the General Secretary by Deng Xiaoping, the paramount leader of China at that time, and other senior party officials (known as the Eight Elders) in 1987, and the students demanded pro-democracy political reforms. Deng labeled the demonstrations as "anti-Party, anti-socialist turmoil." Deng's remark was published and widely circulated, which swelled the number of demonstrators to ten thousands and turned the demonstration into a hunger strike.

The General Secretary at that time was Zhao Ziyang, who advocated several political reforms (dialogues with students, tackling corruption, and increasing press freedom) to ease the pressure from student demonstrators. He also proposed revising Deng's assessment of the demonstrations. This last proposal made the Eight Elders, including those who had so far been sympathetic to Zhao's handling of demonstrations, turn against Zhao. Zhao was removed from the position of General Secretary, and the military crackdown on the hunger strike ensued on June 4th.

Before assuming membership of the Politburo in 1979 and becoming Vice Premier in 1980, Zhao Ziyang was the party leader of Sichuan Province, the most populous province of China whose economy had been devastated when Zhao assumed the leadership. Zhao managed to turn its economy around, increasing industrial production by $81 \%$ and agricultural output by $25 \%$ (BBC 2005). The reason for his promotion to the central government position thus appears to be his ability. Moreover, Zhao never worked together with the Eight Elders and

\footnotetext{
${ }^{37}$ The following two paragraphs are based on Zhao (2009), Zhao Ziyang's own account of his experiences as General Secretary.
} 
other PSC members in power in $1989 .{ }^{38}$ Even though Deng Xiaoping is commonly known as Zhao's mentor, the relationship between the two seems to be a result of meritocracy.

This episode may have been viewed as a cautionary tale for top politicians in China: there are risks involved in promoting officials solely based on their ability. Zhao's lenient approach to the demonstrations resulted in the need of the military crackdown, which could not make the Communist Party popular with citizens. If Zhao had sided with hunger strikers after his dismissal, the Communist Party might have fallen from power.

\section{A.2 Model extensions}

General distribution of $\bar{u}$ In the main text, we assume that $\bar{u}$, the payoff of not promoting provincial leader $i$, is uniformly distributed. If we instead impose no restriction on the cumulative distribution function of $\bar{u}, F$, equation (5) becomes

$$
\frac{\partial F\left(W_{i}^{C_{i}}\right)}{\partial g_{i}}=f\left(W_{i}^{C_{i}}\right) \eta p\left(C_{i}\right) h\left(C_{i}\right)
$$

where $f$ is the probability density function of $\bar{u}$. As a result, connections and growth are complementary if

$$
\frac{p(1)}{p(0)}>\frac{f\left(W_{i}^{0}\right)}{f\left(W_{i}^{1}\right)} \frac{h(0)}{h(1)}
$$

and substitutes if the opposite inequality holds.

Since $W_{i}^{C_{i}}$ depends on $g_{i}$, whether connections and growth are complementary or substitutes may change with $g_{i}$. The issue is whether the functional form of $F(\bar{u})$ can drive the complementarity under condition (7) or substitutability under condition (6).

We only need to consider the functional form of $F(\bar{u})$ around a small range of $\bar{u}$, because the empirically relevant range of the promotion rate is at most 10 percentage points (see Figure 2). There are three cases: $f(\bar{u})$ monotonically increases within the relevant range of $\bar{u}$, monotonically decreases, and changes non-monotonically.

Define $\bar{g}$ as $g_{i}$ that equates $W_{i}^{1}$ and $W_{i}^{0}$. If condition (7) holds (i.e. $\left.p(1) h(1)<p(0) h(0)\right)$, we have $W_{i}^{1}>W_{i}^{0}$ for $g_{i}<\bar{g}$ and $W_{i}^{1}<W_{i}^{0}$ for $g_{i}>\bar{g}$. Furthermore, $W_{i}^{1}-W_{i}^{0}$ monotonically

\footnotetext{
${ }^{38}$ Zhao Ziyang worked in Hua County, Henan province (1939-49), Nanyang Region, Henan province (194951), Guangdong province (1951-67), detained in Guangzhou Military Command Center (1967-70, detained as part of the Cultural Revolution purge), Xiangzhong Mechanics Factory of Lianyuan County, Hunan province (1970-71), Inner Mongolia Autonomous Region (1971-72), Guangdong province (1972-75), and Sichuan Province (1975-80). None of the Eight Elders (Deng Xiaoping, Yang Shangkun, Bo Yibo, Chen Yun, Li Xiannian, Wang Zhen, Peng Zhen, Deng Yingchao) and the other PSC members in 1989 (Li Peng, Qiao Shi, Hu Qili, Yao Yilin) worked in the same place in the same period. The only possible exception is Deng Xiaoping, who in the 1940s was the secretary in charge of the revolutionary base in Shanxi and Hebei, Henan provinces when Zhao was in Hua, a county of Henan province. Although Zhao met Deng during this period (Zhao's land reform policy in Hua county was praised by Deng, according to South China Morning Post 2005), it is unlikely that Zhao worked closely with Deng. Our coding procedure (see footnote 20) also does not regard this as the source of connections.
} 
decreases with $g_{i}$. In this case, the monotonically increasing $f(\bar{u})$ implies that $\frac{f\left(W_{i}^{0}\right)}{f\left(W_{i}^{1}\right)}<1$ for $g_{i}<\bar{g}$ and that this ratio increases with $g_{i}$. Therefore, for a very small value of $g_{i}$, the complementarity arises even under condition (7). On the other hand, the monotonically decreasing $f(\bar{u})$ implies that $\frac{f\left(W_{i}^{0}\right)}{f\left(W_{i}^{1}\right)}<1$ for $g_{i}>\bar{g}$ and that it decreases with $g_{i}$. Therefore, the complementarity arises under condition $(7)$ if $g_{i}$ is very large.

The symmetric argument applies when condition (6) holds (i.e. $p(1) h(1)>p(0) h(0))$. The substitutability arises for large $g_{i}$ if $f(\bar{u})$ monotonically increases and for small $g_{i}$ if $f(\bar{u})$ monotonically decreases.

If $f(\bar{u})$ changes non-monotonically within the relevant range of $\bar{u}, \frac{f\left(W_{i}^{0}\right)}{f\left(W_{i}^{1}\right)}$ is close to one. Thus, condition (6) and condition (7) imply complementarity and substitutability, respectively, as long as $p(1) / p(0)$ is substantially different from $h(0) / h(1)$.

The above arguments indicate that Proposition 1 holds under the general functional form of $F(\bar{u})$ as long as $g_{i}$ does not take extreme values and $p(1) / p(0)$ differs substantially from $h(0) / h(1)$.

PSC's survival probability decreases with ability The probability for the PSC members to remain in power, $p\left(C_{i}\right)$, may decrease with $a_{i}$. More able officials are likely to threaten the power of the incumbent PSC members. However, this threatening effect may be weaker if the officials are connected because connected officials are loyal to the PSC members.

To formalize this idea, denote the PSC's probability of survival in power by $p\left(C_{i}, a_{i}\right)$. We assume that $p\left(1, a_{i}\right)>p\left(0, a_{i}\right)$ for all $a_{i}$, and that, for all $a_{i}$,

$$
\frac{\partial\left[p\left(1, a_{i}\right)-p\left(0, a_{i}\right)\right]}{\partial a_{i}}>0 .
$$

That is, the loyalty fostering role of connections is larger for more talented provincial leaders.

Since $a_{i}$ is unobservable, the PSC forms an expectation on the probability of survival from observed growth, which is given by

$$
\int p\left(C_{i}, a_{i}\right) \phi\left(a_{i} \mid g_{i}\right) d a_{i}
$$

where $\phi\left(a_{i} \mid g_{i}\right)$ is the posterior probability density function of $a_{i}$ given $g_{i}$. Consequently, equation (5) becomes

$$
\frac{\partial F\left(W_{i}^{C_{i}}\right)}{\partial g_{i}}=\mu\left[\eta h\left(C_{i}\right) \int p\left(C_{i}, a_{i}\right) \phi\left(a_{i} \mid g_{i}\right) d a_{i}+X\left(C_{i}\right) Y\left(C_{i}\right)\right]
$$


where

$$
\begin{aligned}
X\left(C_{i}\right) & \equiv R+\eta\left(h\left(C_{i}\right) g_{i}+\left(1-h\left(C_{i}\right)\right) \bar{a}\right) \\
Y\left(C_{i}\right) & \equiv \int p\left(C_{i}, a_{i}\right) \frac{\partial \phi\left(a_{i} \mid g_{i}\right)}{\partial g_{i}} d a_{i}
\end{aligned}
$$

We are interested in whether the condition

$$
\frac{\int p\left(1, a_{i}\right) \phi\left(a_{i} \mid g_{i}\right) d a_{i}}{\int p\left(0, a_{i}\right) \phi\left(a_{i} \mid g_{i}\right) d a_{i}}>\frac{h(0)}{h(1)},
$$

which is the equivalent of condition (6), is sufficient for connections and performance to be complements, and whether the condition

$$
\frac{\int p\left(1, a_{i}\right) \phi\left(a_{i} \mid g_{i}\right) d a_{i}}{\int p\left(0, a_{i}\right) \phi\left(a_{i} \mid g_{i}\right) d a_{i}}<\frac{h(0)}{h(1)}
$$

which is the equivalent of condition (7), is sufficient for connections and performance to be substitutes.

We first consider how differences in $X\left(C_{i}\right)$ and $Y\left(C_{i}\right)$ between connected and unconnected officials depend on $g_{i}$. Whether $X(1)-X(0)$ increases or decreases with $g_{i}$ depends on $h(0) / h(1)$ since

$$
\frac{\partial X(1)-X(0)}{\partial g_{i}}=\eta(h(1)-h(0))
$$

On the other hand, $Y(1)-Y(0)$ always decreases with $g_{i}$ because $p\left(1, a_{i}\right)>p\left(0, a_{i}\right)$ for all $a_{i}$ by assumption and

$$
\frac{\partial^{2} \phi\left(a_{i} \mid g_{i}\right)}{\partial g_{i}^{2}}<0
$$

The latter is because $\phi\left(a_{i} \mid g_{i}\right)$ is normally distributed and $\operatorname{Var}\left(a_{i} \mid g_{i}\right)=\sigma_{a}\left(C_{i}\right)+\sigma_{\varepsilon}\left(C_{i}\right)$ for all $g_{i}$. Finally, when $g_{i}=\bar{a}$, we have $Y(1)>Y(0)$ because $\frac{\partial \phi\left(a_{i} \mid g_{i}\right)}{\partial g_{i}}>0$ for $a_{i}>\bar{a}$ and we assume the inequality (10). Since $Y(1)-Y(0)$ decreases with $g_{i}$, we have $Y(1)=Y(0)$ for some $g_{i}>\bar{a}$. Denote such $g_{i}$ by $\tilde{g}$. We have $Y(1)<Y(0)$ for $g_{i}>\tilde{g}$.

Suppose $h(0)>h(1)$. It implies that we have $X(1)>X(0)$ if $g_{i}<\bar{a}$ and $X(1)<X(0)$ instead if $g_{i}>\bar{a}$. Therefore, we have $X(1) Y(1)>X(0) Y(0)$ for $g_{i}<\bar{a}$ and $g_{i}>\tilde{g}$. In these cases, condition (12) is sufficient for the complementarity to arise. Even when $X(1) Y(1)<$ $X(0) Y(0)$, we will have equation (11) to be larger for $C_{i}=1$ (i.e. complementarity) as long as $h(0) / h(1)$ is relatively much small to the left hand of inequality (12). A symmetric argument implies that condition (13) is sufficient for substitutability as long as $g_{i}$ is not too large or too small.

Suppose $h(0)<h(1)$ instead. In this case, we have $X(1)<X(0)$ if $g_{i}<\bar{a}$ and $X(1)>$ 
$X(0)$ instead if $g_{i}>\bar{a}$. Thus, $X(1) Y(1)<X(0) Y(0)$ if and only if $g_{i}<\bar{a}$ or $g_{i}>\tilde{g}$. Consequently, condition (12) is sufficient for complementarity as long as $g_{i}$ is not too large or too small. ${ }^{39}$

In summary, a version of Proposition 1 in which conditions (6) and (7) are replaced with (12) and (13), respectively, holds as long as $g_{i}$ is not too small or large and, if $h(0)>h(1)$, $h(0)$ is sufficiently close to $h(1)$.

Strategic provincial leader Given the promotion scheme, it is natural for provincial leaders to exert an effort to boost the economic growth of the province. Now, we modify the model to incorporate such strategic behavior of the provincial leader. Provincial leader $i$ obtains the payoff of $r$ if promoted and zero otherwise. Provincial growth, $g_{i}$, is now determined by the following equation:

$$
g_{i}=a_{i}+e_{i}+\varepsilon_{i}
$$

where $e_{i}$ is the effort made by $i{ }^{40}$ The disutility from making an effort for $i$ is $\kappa\left(e_{i}\right)$ with $\kappa^{\prime}>0$ and $\kappa^{\prime \prime}>0$. The timing of events is as follows. First, nature picks the value of $a_{i}$, unobservable to both the PSC and the provincial leader. ${ }^{41}$ Second, provincial leader $i$ chooses $e_{i}$. Third, nature picks the value of $\varepsilon_{i}$, and thus $g_{i}$ is observed by all players. Finally, the PSC decides whether to promote $i$.

The expected ability conditional on the observed growth is now given by

$$
E\left(a_{i} \mid g_{i}\right)=h\left(C_{i}\right)\left(g_{i}-\tilde{e}_{i}\right)+\left[1-h\left(C_{i}\right)\right] \bar{a},
$$

where $\tilde{e}_{i}$ denotes the optimal choice of effort by $i$. When choosing $e_{i}$, provincial leader $i$ knows that the PSC will promote $i$ if

$$
p\left(C_{i}\right)\left[R+\eta\left\{h\left(C_{i}\right)\left(a_{i}+e_{i}+\varepsilon_{i}-\tilde{e}_{i}\right)+\left[1-h\left(C_{i}\right)\right] \bar{a}\right\}\right] \geq \bar{u} .
$$

Provincial leader $i$ chooses $e$ that maximizes the payoff $q(e) r-\kappa(e)$, where $q(e)$ is the probability that the condition (16) holds. Since $i$ does not know his own ability, the condition (16) suggests that the optimal effort level only differs by $C_{i}$. Denote this optimal effort by

\footnotetext{
${ }^{39}$ When $h(0)<h(1)$, condition (13) never holds by the assumption that $p\left(1, a_{i}\right) \geq p\left(0, a_{i}\right)$ for all $a_{i}$.

${ }^{40} \mathrm{We}$ might consider a situation where ability and effort are complements: $g_{i}=a_{i} e_{i}+\varepsilon_{i}$. This case is intractable to analyze although it can be shown that the interdependence between connections and growth now depends on the equilibrium effort level as well as on $p\left(C_{i}\right)$ and $h\left(C_{i}\right)$, which may or may not offset the connection effects.

${ }^{41}$ The assumption that the provincial leader does not know his own ability follows the standard careerconcern model (Holmström 1982; Persson and Tabellini 2000). It implies that a provincial leader does not know ex ante to what extent he is capable of running a provincial economy and of running the central government if promoted. This assumption certainly affects the optimal effort choice by provincial leaders. However, as we will see, the interdependent role of connections and growth in promotion does not hinge on the optimal effort level. Thus, this assumption is innocuous for our purpose.
} 
$e^{*}\left(C_{i}\right)$. Once $g_{i}$ has been observed, the probability of $i$ 's promotion is

$$
F\left[p\left(C_{i}\right)\left[R+\eta\left\{h\left(C_{i}\right)\left[g_{i}-e_{i}^{*}\left(C_{i}\right)\right]+\left[1-h\left(C_{i}\right)\right] \bar{a}\right\}\right]\right]
$$

where we exploit $\tilde{e}=e_{i}^{*}\left(C_{i}\right)$ by rational expectation. Differentiating this expression with respect to $g_{i}$ yields equation $(5)$.

Connections affect the average ability The average ability, $\bar{a}$, may depend on $C_{i}$. Since connected provincial leaders are known to the PSC members when they assume provincial office, they are likely to be a selected sample of officials with higher ability: $\bar{a}\left(C_{i}=1\right)>$ $\bar{a}\left(C_{i}=0\right)$. Alternatively, connected provincial leaders are those relying on connections to climb the promotion ladder in the Communist Party while unconnected ones are those relying on their competence. In this case, we would have $\bar{a}\left(C_{i}=1\right)<\bar{a}\left(C_{i}=0\right)$.

With the uniform distribution of $\bar{u}$, allowing $\bar{a}$ to depend on $C_{i}$ does not affect the analysis as $\partial F\left(W_{i}^{C_{i}}\right) / \partial g_{i}$ does not depend on $a_{i}$. With more general distribution functions of $\bar{u}$, the exact range of $g_{i}$ in which Proposition 1 holds will change because $\bar{a}$ linearly affects $W_{i}^{C_{i}}$. Qualitatively, however, the same conclusion applies as the analysis above (i.e. Proposition 1 holds as long as $g_{i}$ does not take extreme values and $p(1) / p(0)$ substantially differs from $h(0) / h(1))$.

\section{A.3 A model of promotion as an incentive scheme}

An alternative model of promotion is that the PSC cares about provincial economic growth per se, not the ability of those to be promoted. Promotion is used as an incentive scheme where growth is determined by provincial leaders' effort, not their ability.

Suppose that the PSC derives the utility from the share of tax revenues in province $i$ that its leader $i$ (with his connection status $C_{i}$ ) contributes to them. Assuming that tax revenues increase with growth, $g_{i}$, we can write the PSC's payoff as follows:

$$
\alpha\left(C_{i}\right) g_{i}
$$

where $\alpha\left(C_{i}\right)$ is the extent to which provincial leader $i$ shares his province's tax revenue with the PSC. We have $\alpha(1)>\alpha(0)$ if connections make provincial leaders more obliged to share their tax revenue with the PSC. If unconnected provincial leaders need to share more tax revenues with the PSC to compensate for the lack of loyalty through connections, we have $\alpha(1)<\alpha(0)$.

Economic growth in province $i$ is determined by:

$$
g_{i}=e_{i}+\varepsilon_{i}
$$

where $e_{i}$ is the effort exerted by the leader of province $i$ and $\varepsilon_{i}$ the stochastic shock to growth, distributed by the cumulative distribution function $G$ with mean 0 . 
Provincial leader $i$ obtains the payoff of $r$ if promoted and zero otherwise, and the disutility from making an effort for $i$ is $\kappa\left(e_{i}\right)$ with $\kappa^{\prime}>0$ and $\kappa^{\prime \prime}>0$.

Assume that the PSC can commit to promoting provincial leader $i$ if $\alpha\left(C_{i}\right) g_{i} \geq \bar{u}$, where $\bar{u}$ is the performance of an alternative candidate. For simplicity, we assume $\bar{u}$ to be uniformly distributed in the interval $[-1 / 2 \nu, 1 / 2 \nu]$.

We first analyze the provincial leader's behavior. The probability of promotion given $e_{i}$ is:

$$
\begin{aligned}
\operatorname{Pr}\left(\alpha\left(C_{i}\right)\left(e_{i}+\varepsilon_{i}\right) \geq \bar{u}\right) & =\int\left[\frac{1}{2}+\nu \alpha\left(C_{i}\right)\left(e_{i}+\varepsilon_{i}\right)\right] d G\left(\varepsilon_{i}\right) \\
& =\frac{1}{2}+\nu \alpha\left(C_{i}\right) e_{i},
\end{aligned}
$$

with the last equality by $\int \varepsilon_{i} d G\left(\varepsilon_{i}\right)=0$.

Provincial leader $i$ chooses $e_{i}$ to maximize

$$
\left[\frac{1}{2}+\nu \alpha\left(C_{i}\right) e_{i}\right] r-\kappa\left(e_{i}\right) .
$$

The first-order condition is given by

$$
\nu \alpha\left(C_{i}\right) r=\kappa^{\prime}\left(e_{i}\right) .
$$

By $\kappa^{\prime \prime}>0$, there is the unique solution for $e_{i}, e_{i}^{*}\left(C_{i}\right)$, with $e_{i}^{*}(1)>e_{i}^{*}(0)$ if and only if $\alpha(1)>\alpha(0)$.

Given this optimal behavior, we now look at the marginal probability of promotion with respect to growth. Once $\varepsilon_{i}$ is observed, the probability of promotion is given by

$$
\operatorname{Pr}\left(\alpha\left(C_{i}\right) g_{i} \geq \bar{u}\right)=\frac{1}{2}+\nu \alpha\left(C_{i}\right) g_{i} .
$$

Differentiating this expression with respect to $g_{i}$ yields:

$$
\frac{\partial \operatorname{Pr}\left(\alpha\left(C_{i}\right) g_{i} \geq \bar{u}\right)}{\partial g_{i}}=\nu \alpha\left(C_{i}\right) .
$$

Consequently, if we have $\alpha(1)>\alpha(0)$, this expression is larger for $C_{i}=1$ and thus connections and growth are complementary. If $\alpha(1)<\alpha(0)$, they are substitutes.

The above argument depends on the assumption that the PSC's commitment to this promotion scheme is credible. Once growth has been realized, the PSC is indifferent between promoting the high-performing provincial leader and reneging on the promise (and even prefers not promoting if promotion is costly). Credible commitment is plausible if the PSC expects to remain in power for a certain period of time and thus needs to build the reputation to reward good performance for future provincial leaders. Otherwise, we need an assumption that the PSC cares about the ability of those promoted so that the PSC has an incentive to 
promote those who have achieved high growth (see Fairburn and Malcomson 2001).

\section{A.4 Additional Robustness Checks}

Definitions of Promotion The first set of additional robustness checks on our key finding concerns the definition of promotion. Tao et al. (2010) suggest that the definition of promotion of provincial leaders should include three additional appointments. Thus, we broaden the definition of promotion step by step in Table A.3. Column 1 changes the definition of promotion so that becoming a minister is also regarded as promotion for provincial governors. Ministers are officially ranked equal to provincial secretaries. As governors are ranked below secretaries in each province, becoming ministers can be seen as promotion for governors. Seven additional leadership spells end with promotion in this definition.

Column 2 further changes the definition of promotion, including appointments of both secretaries and governors to become vice-chairmen of the National People's Congress (the lower house of the Chinese parliament). Four additional leadership spells are then coded as promotions. In column 3, six more cases where provincial leaders become vice-chairmen of the CPPCC (the upper house of the Chinese parliament) are also coded as promotion. Officially, these positions are ranked higher than provincial leadership positions. Due to the nature of parliaments in the Chinese political regime, they can also be regarded as ceremonial.

Table A.3 shows that our finding of the complementarity of connections and growth is robust to these different definitions of promotion, with estimated coefficients fairly stable across definitions.

Other individual and province characteristics Table A.4 controls for the individual and province characteristics and their interactions with (demeaned) growth that are not included in Table 2. Column 1 controls for the indicator of ruling the native province. Column 2 controls for provincial growth over the five-year period before assuming leadership. Column 3 controls for whether the provincial leader has graduated from college. Column 4 controls for the indicator of provincial leaders being a princeling. Column 5 checks if connected leaders are simply assigned to provinces that PSC members were born in and thus have a great deal of knowledge about. Finally, column 6 controls for all these variables (including those controlled for in Table 2) and their interactions with growth. In all these columns, the estimated coefficients on the connection indicator and its interaction term with growth change little from the estimates in column 4 of Table 2, suggesting that the main result is not driven by these omitted variables.

\section{A.5 Other Connection Sources}

Table A.5 investigates whether other sources of social connections are of importance for

promotion. For this purpose, we replace $C_{i t}$ in equation (8) with alternative independent 
variables. In column 1, we use a dummy that equals one if a provincial leader graduated from the same college as a current PSC member within a period of three years before or after. Such provincial leaders may have met a PSC member while in college. In column 2 , we use an indicator of provincial leaders having graduated from the same college as a current PSC member at any point in time. Graduating from the same college may reduce the cost of communication, even if they did not attend the college at the same time. ${ }^{42}$ In column 3, we define connections as being born in the same province, which may also reduce the cost of communication. Table A.5 shows that none of these sources of connections have any significant effect on the probability of promotion.

\section{A.6 Annually Observed Growth}

In Section 6.2, we argue that if the complementarity of connections and performance is driven by the communication-enhancing role of connections, the degree of complementarity decreases with each provincial leader's tenure. Below we present an extended model to formalize the argument.

The Model In this extended model, the PSC observes annual provincial economic growth under the rule of provincial leader $i$, which we denote by $g_{i t}$, where $t$ is the number of years during which $i$ is in office. We assume that growth is given by the following equation:

$$
g_{i t}=a_{i}+\varepsilon_{i t}
$$

where $\varepsilon_{i t}$ is normally distributed with mean zero and variance $\sigma_{\varepsilon}\left(C_{i}\right)$. For simplicity, we assume that $\varepsilon_{i j}$ is uncorrelated with $\varepsilon_{i k}$, for $k \neq j$.

Consequently, the PSC's expected utility from promoting $i$ who has been in office for $t$ years is given by:

$$
W_{i}^{C_{i}} \equiv E\left[u\left(R, a_{i}\right) \mid\left\{g_{i \tau}\right\}_{\tau=1}^{t}\right]=p\left(C_{i}\right)\left[R+\eta E\left(a_{i} \mid\left\{g_{i \tau}\right\}_{\tau=1}^{t}\right)\right]
$$

The rest of the model is the same as the one in Section 3.1.

Analysis $E\left(a_{i} \mid\left\{g_{i \tau}\right\}_{\tau=1}^{t}\right)$ is given by the weighted average of the mean annual growth, $\bar{g}_{i t} \equiv \sum_{\tau=1}^{t} g_{i \tau} / t$, and the prior mean ability, $\bar{a}$, with the weights being the relative precision of growth and ability:

$$
E\left(a_{i} \mid\left\{g_{i \tau}\right\}_{\tau=1}^{t}\right)=h\left(C_{i}, t\right) \bar{g}_{i t}+\left(1-h\left(C_{i}, t\right)\right) \bar{a},
$$

\footnotetext{
${ }^{42}$ Many of the top politicians in China graduated from Tsinghua University, one of the most prestigious colleges in China, and they are known as the Tsinghua clique.
} 
where

$$
h\left(C_{i}, t\right) \equiv \frac{t \sigma_{a}\left(C_{i}\right)}{t \sigma_{a}\left(C_{i}\right)+\sigma_{\varepsilon}\left(C_{i}\right)}
$$

Hence, the marginal increase in the promotion probability with respect to the average economic growth $\bar{g}_{i t}$ is:

$$
\frac{\partial F\left(W_{i}^{C_{i}}\right)}{\partial \bar{g}_{i t}}=\mu \eta p\left(C_{i}\right) h\left(C_{i}, t\right) .
$$

If $p(1) h(1, t)>p(0) h(0, t)$, the complementarity between connections and performance arises. This condition holds either when $p(1)>p(0)$ (i.e. loyalty-fostering) or when $h(1, t)>$ $h(0, t)$ (i.e. communication-enhancing). Differentiating $h(1, t)-h(0, t)$ with respect to $t$ yields:

$$
\begin{aligned}
\frac{\partial(h(1, t)-h(0, t))}{\partial t} & =\frac{\sigma_{a}(1) \sigma_{\varepsilon}(1)}{\left[t \sigma_{a}(1)+\sigma_{\varepsilon}(1)\right]^{2}}-\frac{\sigma_{a}(0) \sigma_{\varepsilon}(0)}{\left[t \sigma_{a}(0)+\sigma_{\varepsilon}(0)\right]^{2}} \\
& =\frac{\left[\sigma_{a}(0) \sigma_{\varepsilon}(1)-\sigma_{a}(1) \sigma_{\varepsilon}(0)\right]\left[t^{2} \sigma_{a}(1) \sigma_{a}(0)-\sigma_{\varepsilon}(1) \sigma_{\varepsilon}(0)\right]}{\left[t \sigma_{a}(1)+\sigma_{\varepsilon}(1)\right]^{2}\left[t \sigma_{a}(0)+\sigma_{\varepsilon}(0)\right]^{2}}
\end{aligned}
$$

When $h(1, t)>h(0, t)$, we have

$$
\sigma_{a}(0) \sigma_{\varepsilon}(1)<\sigma_{a}(1) \sigma_{\varepsilon}(0)
$$

Therefore, $h(1, t)-h(0, t)$ decreases with $t$ for $t \geq \tilde{t}$ where

$$
\tilde{t}=\left[\frac{\sigma_{\varepsilon}(1) \sigma_{\varepsilon}(0)}{\sigma_{a}(1) \sigma_{a}(0)}\right]^{\frac{1}{2}}
$$

If the prior ability is equally informative to growth, then $\tilde{t}=1$. In this case, the difference in equation (17) between $C_{i}=1$ and $C_{i}=0$ decreases with $t$. In other words, the complementarity due to the communication-enhancing role of connections weakens with the tenure of the provincial leader.

\section{A.7 Definition of variable names used in tables}

\section{A.7.1 Measures of promotion}

Promoted The indicator of getting promoted where promotion is defined as becoming a member of the Politburo, a Vice Premier, and a State Councilor for secretaries, a member of the PSC for Politburo-member secretaries, and a provincial secretary for governors.

Minister The indicator of getting promoted according to the definition of promotion that includes becoming a minister for governors. 
NPC The indicator of getting promoted according to the definition of promotion that further includes becoming the vice-chairman of the NPC for both secretaries and governors.

CPPCC The indicator of getting promoted according to the definition of promotion that further includes becoming the vice-chairman of the CPPCC for both secretaries and governors.

\section{A.7.2 Measures of connection}

Connection The indicator of being connected to at least one of the current members of the PSC where connection is defined as working in the same workplace in the same period in the past.

Class The indicator of being connected to at least one of the current members of the PSC where connection is defined as graduating from the same college within a range of three years.

Alumni The indicator of being connected to at least one of the current members of the PSC where connection is defined as graduating from the same college irrespective of the graduation year.

Birth province The indicator of being connected to at least one of the current members of the PSC where connection is defined as being born in the same province.

\section{A.7.3 Leadership spell level variables}

Term length The number of years in office.

Transfer from center The fiscal transfer from the central government to the province that the provincial leader is ruling. The annual data is averaged over each leadership spell.

Loan to Deposit Ratio The ratio of total bank loans to total bank deposits. The annual data is averaged over each leadership spell.

Number of new SEZs The number of prefecture-level municipalities which obtain the Special Economic Zone status. The annual data is averaged over each leadership spell.

\section{A.7.4 Other time-variant variables}

Growth The average annual real provincial GDP growth since assuming office. 
PSC work province The indicator of ruling the province where at least one current member of the PSC used to work.

PSC home province The indicator of ruling the province where at least one current member of the PSC was born.

Future/past connection The indicator of being unconnected to any current members of the PSC but being connected to at least one past or future member of the PSC, where connection is defined as working in the same workplace in the same period in the past.

Workplace The indicator of being unconnected to any current members of the PSC but having worked in the workplace in which at least one current member of the PSC used to work in a different period.

Politburo connection The indicator of being unconnected to any current members of the PSC but being connected to at least one member of the Politburo, where connection is defined as working in the same workplace in the same period in the past.

\section{A.7.5 Other time-invariant variables}

Age The age in the year of assuming office (thus time-invariant for each leadership spell).

Previous growth The average annual real provincial GDP growth for the five-year period before assuming office.

College graduate The indicator of having graduated from college.

Served in center The indicator of having assumed positions in the central government.

Home The indicator of ruling the province where the provincial leader was born.

Princeling The indicator of being a princeling (i.e. the son or the son-in-law of a prominent Communist Party official)

\section{References}

[1] BBC. 2005. "Obituary: Zhao Ziyang." http://news.bbc.co.uk/2/hi/asiapacific/2989335.stm

[2] Persson, Torsten, and Guido Tabellini. 2000. Political Economics: Explaining Economic Policy. Cambridge, Massachusetts: MIT Press. 
[3] South China Morning Post. 2005. "The Reformist Premier Who Ended His Life as a Prisoner." http://www.scmp.com/article/486026/reformist-premier-who-ended-his-lifeprisoner

[4] Zhao, Ziyang. 2009. Prisoner of the State: The Secret Journal of Premier Zhao Ziyang. New York: Simon \& Schuster. 
Table A.1: Correlations of promotion and growth for connected and unconnected provincial leaders

(Dependent variable: Promoted)

\begin{tabular}{|c|c|c|}
\hline Sample: & $\begin{array}{c}(1) \\
\text { Connected }\end{array}$ & $\begin{array}{c}(2) \\
\text { Unconnected }\end{array}$ \\
\hline Growth & $\begin{array}{l}3.749^{* *} \\
(1.596) \\
{[0.046]}\end{array}$ & $\begin{array}{c}0.283 \\
(0.454) \\
{[0.562]}\end{array}$ \\
\hline $\begin{array}{l}\text { Fixed Effects } \\
\text { \# clusters } \\
\text { \# observations }\end{array}$ & $\begin{array}{c}\mathrm{Y} \\
26 \\
205\end{array}$ & $\begin{array}{c}\mathrm{Y} \\
31 \\
761\end{array}$ \\
\hline \multicolumn{3}{|c|}{$\begin{array}{l}\text { Notes: Standard errors clustered at the province level are reported in parenthesis. Reported in } \\
\text { brackets are the p-values for the significance of the coefficient on Growth by the wild cluster } \\
\text { bootstrap-t (Cameron et al. 2008). The variable Growth is the average provincial GDP growth } \\
\text { since the provincial leader assumes office. Columns (1) and (2) restrict the sample to connected } \\
\text { and unconnected provincial leaders, respectively. All columns control for dummies of the number } \\
\text { of years in office (two to twelve), office-by-province fixed effects, and office-by-year fixed effects. } \\
* \text { Significant at } 10 \%, * * 5 \%, * * * 1 \% \text {. }\end{array}$} \\
\hline
\end{tabular}


Table A.2: Is the degree of complementarity different by the number of connections?

\begin{tabular}{lc}
\multicolumn{2}{c}{ (Dependent variable: Promoted) } \\
\hline \hline \multicolumn{1}{c}{$(1)$} \\
\hline Growth & 0.335 \\
& $(0.430)$ \\
1 Connection & 0.032 \\
& $(0.027)$ \\
1 Connection * Growth & $2.050^{*}$ \\
& $(1.157)$ \\
2 Connections & 0.057 \\
& $(0.056)$ \\
2 Connections * Growth & 3.642 \\
& $(2.640)$ \\
\hline Fixed Effects & $\mathrm{Y}$ \\
\# clusters & 31 \\
\# observations & 966 \\
\hline \hline
\end{tabular}

Notes: Standard errors clustered at the province level are reported in parenthesis. The variable Growth is the average provincial GDP growth since the provincial leader assumes office, normalized by subtracting the sample mean. The variables 1 Connection and 2 Connections are the indicators that provincial leaders are connected to one and two, respectively, member(s) of the PSC. Controls include dummies of the number of years in office (two to twelve), office-by-province fixed effects, and office-by-year fixed effects.

* Significant at $10 \%, * * 5 \%, * * * 1 \%$. 
Table A.3: Robustness to alternative definitions of promotion

\begin{tabular}{lccc}
\hline \hline & $(1)$ & $(2)$ & $(3)$ \\
Dependent variable: & Minister & NPC & CPPCC \\
\hline Connection & 0.038 & 0.033 & 0.023 \\
& $(0.026)$ & $(0.026)$ & $(0.026)$ \\
Growth & 0.441 & 0.328 & 0.273 \\
& $(0.452)$ & $(0.460)$ & $(0.423)$ \\
Connection * Growth & $2.309^{* *}$ & $2.201^{* *}$ & $2.374^{* *}$ \\
& $(0.869)$ & $(0.915)$ & $(0.919)$ \\
& {$[0.028]$} & {$[0.050]$} & {$[0.032]$} \\
\hline Fixed Effects & $\mathrm{Y}$ & $\mathrm{Y}$ & $\mathrm{Y}$ \\
\# clusters & 31 & 31 & 31 \\
\# observations & 966 & 966 & 966 \\
\hline \hline
\end{tabular}

Notes: Standard errors clustered at the province level are reported in parenthesis. Reported in brackets are the $p$-values for the significance of the coefficient on Connection * Growth by the wild cluster bootstrap-t (Cameron et al. 2008). See Appendix Section A.7 for variable definitions. However, the variable Growth is normalized by subtracting the sample mean. All columns control for dummies of the number of years in office (two to twelve), office-by-province fixed effects, and office-by-year fixed effects.

* Significant at $10 \%, * * 5 \%, * * * 1 \%$. 


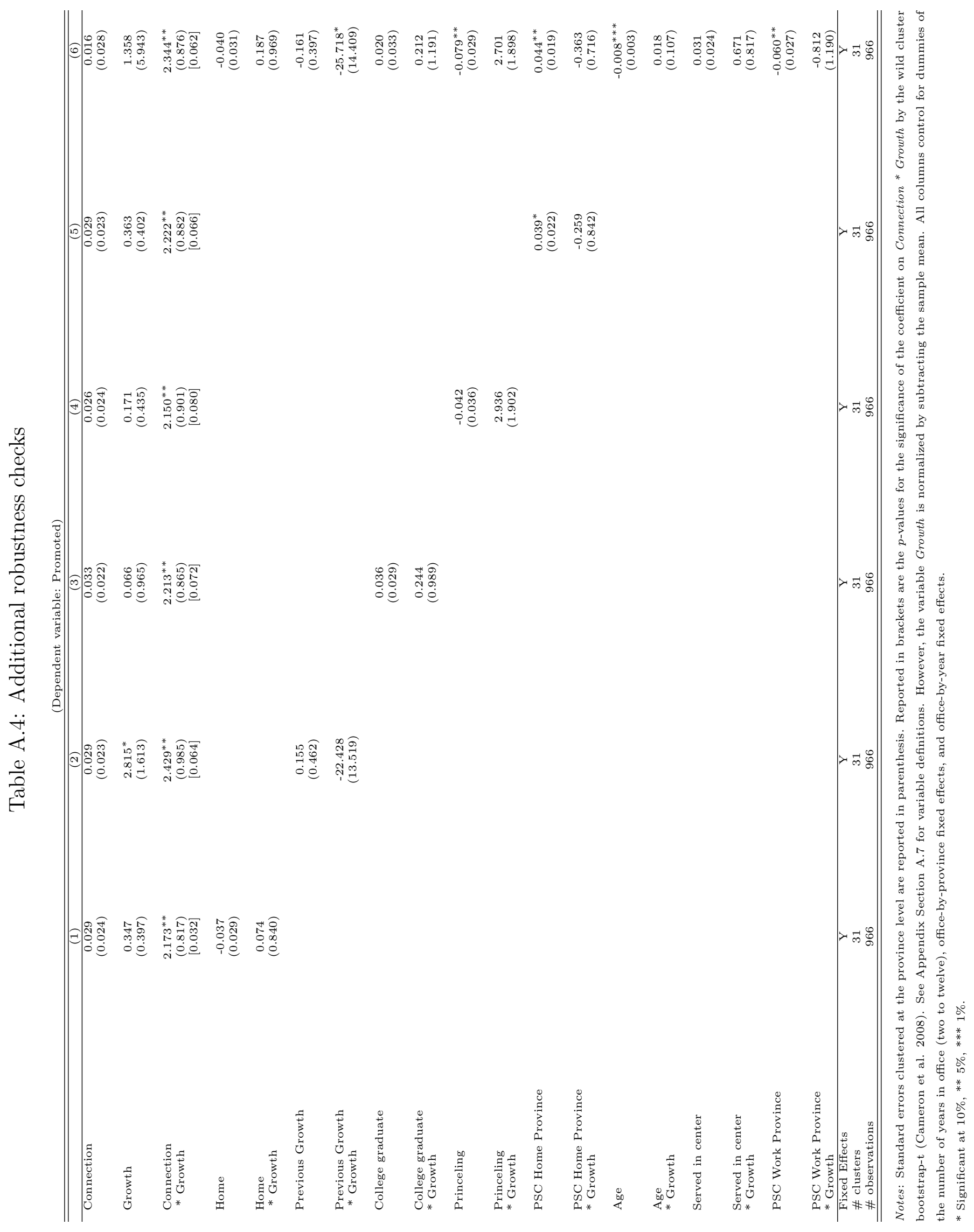




\section{Table A.5: Other sources of connections}

(Dependent variable: Promoted)

\begin{tabular}{lccc}
\hline \hline Definition of connection: & $(1)$ & $(2)$ & $(3)$ \\
& Class & Almuni & Birth province \\
\hline Other connection & 0.117 & 0.061 & 0.000 \\
& $(0.071)$ & $(0.046)$ & $(0.020)$ \\
Growth & 0.662 & 0.750 & 0.564 \\
& $(0.442)$ & $(0.531)$ & $(0.538)$ \\
Other connection * Growth & -0.177 & -0.589 & 0.458 \\
& $(1.851)$ & $(1.232)$ & $(0.787)$ \\
& {$[0.940]$} & {$[0.634]$} & {$[0.590]$} \\
\hline Fixed Effects & $\mathrm{Y}$ & $\mathrm{Y}$ & $\mathrm{Y}$ \\
\# clusters & 31 & 31 & 31 \\
\# observations & 966 & 966 & 966 \\
\hline \hline
\end{tabular}

Notes: Standard errors clustered at the province level are reported in parenthesis. Reported in brackets are the $p$-values for the significance of the coefficient on Other connection * Growth by wild cluster bootstrap-t (Cameron et al. 2008). The variable Other connection refers to the variable mentioned at the top of each column. See Appendix Section A.7 for variable definitions. However, the variable Growth is normalized by subtracting the sample mean. All columns control for dummies of the number of years in office (two to twelve), office-by-province fixed effects, and office-by-year fixed effects.

* Significant at $10 \%,{ }^{* *} 5 \%,{ }^{* * *} 1 \%$. 